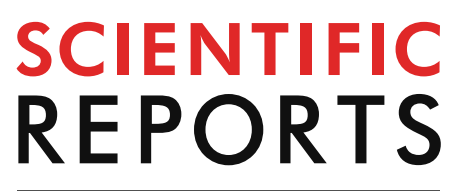

natureresearch

Check for updates

\title{
Chemical composition
} and anti-oxidant potential on essential oils of Thymus quinquecostatus Celak. from Loess Plateau in China, regulating Nrf2/Keap1 signaling pathway in zebrafish

Ting $\mathrm{He}^{1}$, Xiao $\mathrm{Li}^{1}$, Xiaoping Wang ${ }^{1}$, Xiao Xu ${ }^{1}$, Xin Yan ${ }^{1}$, Xiang $\mathrm{Li}^{1}$, Siqi Sun ${ }^{1}$, Ying Dong ${ }^{1}$, Xueyang Ren ${ }^{1}$, Xiaoyun Liu $^{1}$, Yu Wang ${ }^{1}$, Hong Sui ${ }^{2}$, Oing Xia ${ }^{3 \bowtie}$ \& Gaimei She ${ }^{1 \bowtie}$

Chemical profile and antioxidant potency of essential oils (EOs) of Thymus quinquecostatus Celak. (thyme oils) obtained from Loess Plateau in China had been studied. 130 constituents of thyme oils were determined using gas chromatography-mass spectrometry (GC-MS) and carvacrol ethyl ether was firstly reported as a new natural product, which has been used as a synthetic flavoring substance with no safety concern. The thyme oils showed the anti-oxidant activity using 2,2 diphenyl-1-picrylhydrazyl (DPPH), 2,2'-azino-bis-(3-ethylbenzothiazoline-6-sulfonate) (ABTS), ferric reducing antioxidant power (FRAP) and thiobarbituric acid reactive substances (TBARS) and conferred protection against oxidative stress in zebrafish. In addition, a class of carvacrol analogues was found to develop as potential natural antioxidant products of thyme oils from Loess Plateau by the correlation analysis. YL-thyme oil performed the best antioxidant activity in this research, which could be recommended as preferred sources of thyme oils. Furthermore, YL-thyme oil exhibited a potent antioxidant capacity by reactive oxygen species (ROS) scavenging, enhancing the endogenous antioxidant system, inhibiting lipid peroxidation and activation of Keap1/Nrf2 pathway in zebrafish.

Oxidative stress is a phenomenon associated with pathogenetic mechanisms of several diseases including atherosclerosis, neurodegenerative diseases, cancer, diabetes mellitus, inflammatory diseases, as well as psychological diseases or aging processes. It is defined as an imbalance between production of free radicals and reactive metabolites, so-called oxidants or $\mathrm{ROS}^{1}$. Most of ROS such as superoxide anion $\left(\mathrm{O}^{2-}\right)$, hydroxyl radical $(\mathrm{OH})$, hydrogen peroxide $\left(\mathrm{H}_{2} \mathrm{O}_{2}\right)$ and organic peroxides, are generated in the cells by mitochondrial respiratory chain ${ }^{2}$. Excessive ROS can damage cell functionality as they can harm cellular lipids, proteins and DNA ${ }^{3}$. The organism contains a complex and carefully balanced cascade of antioxidant enzymes, of which the superoxide dismutase (SOD) and catalase (CAT) are regarded as the first line of the antioxidative enzyme system against ROS such as superoxide and $\mathrm{H}_{2} \mathrm{O}_{2}$ generated during oxidative stress ${ }^{4}$. The kelch-like ECH-associated protein 1/nuclear factor E2-related factor 2 (Keap1/Nrf2) signaling pathway plays a central role in protecting the body from oxidative damage. The Nrf2 transcription factor is tightly regulated by the repressor protein, Keap1, in the cytoplasm. Under oxidative stress, Nrf2 is released from the Nrf2/Keap1 complex and is translocated to

\footnotetext{
${ }^{1}$ School of Chinese Materia Medica, Beijing University of Chinese Medicine, Beijing 102488, China. ${ }^{2}$ School of Chinese Pharmacy, Ningxia Medical University, Yinchuan 750004, China. ${ }^{3}$ Biology Institute, Qilu University of Technology (Shandong Academy of Sciences), Jinan 250103, China. ${ }^{凶}$ email: sdxq1021@163.com; shegaimei@126.com
} 


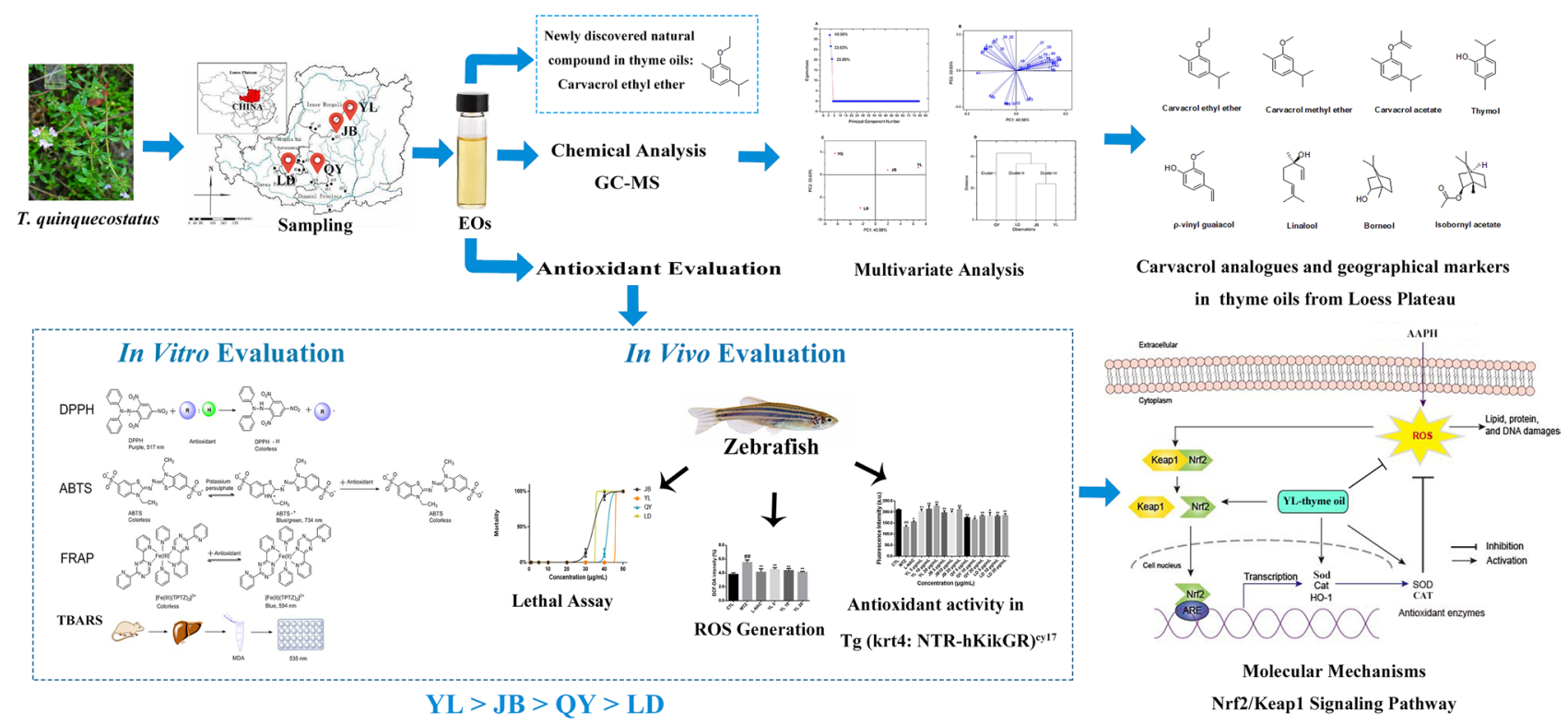

Figure 1. Graphical abstract.

the nucleus. Subsequently, it binds to antioxidant-response elements (AREs) and upregulates the expression of downstream genes, such as Sod1, Cat and Hmox1, which in turn, activates cellular antioxidant defensive capacity ${ }^{5}$.

The beneficial effects of antioxidants on the maintenance of health in human have become an important subject that has engaged many scientists across the world over the last decade. The antioxidants from plants have been reported to inhibit the propagation of free radical reactions and protect the human body from various diseases $^{6}$. The genus Thymus belongs to the Lamiaceae family, and contains more than 300 species of aromatic perennial herbaceous plants with valuable medicinal properties ${ }^{7}$. T. quinquecostatus, commonly called thyme ('thyme' in this study refers to T. quinquecostatus), was distributed in the northwest of China, mainly in the Loess Plateau. It is locally used as a seasoning and also has natural preservative effects which makes it widely used as a green harmless flavor additive. Thyme was widely used to treat stroke, cold, dyspepsia, toothache, acute gastroenteritis, hypertension, chronic eczema and other diseases as folk medicines and was used alone or in combination with other herbal medicines for cancer treatment. In our previous researches, the antioxidant activities of different polar fractions of T. quinquecostatus had been evaluated. Meanwhile, chemical compositions, like flavonoids and phenolic acids, were also identified and full-scale qualitative and quantitative methods were successfully applied to the quality evaluation of T. quinquecostatus ${ }^{8,9}$.

Thyme oil has been widely used in food industry, pharmaceutical and cosmetic due to its various biological activities, including antioxidant, anti-inflammatory, antitumor and antimicrobial effects ${ }^{10}$. To our best knowledge, remarkable chemo diversity of the same plant species has been reported due to the differences in chemotype, plant genotype, harvesting time, cultivation and climatic peculiarities and other factors; therefore, investigation of the same plant species from different geographic zones may considerably expand the existing knowledge on essential oils (EOs).

And previous reports mainly focused on thyme oils from one certain district, while the diversity of chemical compositions in thyme oils collected from different producing areas has not yet been studied and the relationship between thyme oils compositions and biological activities is rarely mentioned. Moreover, most of the antioxidant researches on thyme oils focused on in vitro studies and the underlying mechanism of antioxidant activity of thyme oils is still unclear.

Considering polymorphism of Thymus genus plants as well as the variety of factors, which may influence EO compositions and their biological activities, T. quinquecostatus cultivated in the Loess Plateau of four main producing regions, namely YL (Shaanxi province), JB (Shaanxi province), QY (Gansu province) and LD (Ningxia Hui Autonomous Region) had been selected for the present study. Combined with statistical analysis, the compositions of thyme oils from the four producing areas were comparatively analyzed and the correlations between these thyme oil components and anti-oxidative activities were also discussed. Besides, their antioxidant potentials were evaluated by the in vitro assays (DPPH, ABTS, FRAP and TBARS) as well as in the in vivo zebrafish model. Moreover, the effects of thyme oils on expression of genes related to oxidative stress were investigated. This study provides a better understanding of antioxidant capacities of thyme oils and the underlying molecular mechanisms. Figures 1 and 2 are graphical abstract and technical route of this study, respectively.

\section{Materials and methods}

Plant materials. The aerial parts of T. quinquecostatus were collected from $\mathrm{YL}\left(38^{\circ} 17^{\prime} 4.89^{\prime \prime} \mathrm{N}, 109^{\circ} 43^{\prime} 44.43^{\prime \prime} \mathrm{E}\right)$ and JB $\left(37^{\circ} 35^{\prime} 55.44^{\prime \prime} \mathrm{N}, 108^{\circ} 47^{\prime} 26.40^{\prime \prime} \mathrm{E}\right)$ in Shaanxi province, QY $\left(35^{\circ} 42^{\prime} 36.62^{\prime \prime} \mathrm{N}, 107^{\circ} 38^{\prime} 17.42^{\prime \prime} \mathrm{E}\right)$ in Gansu province and $\operatorname{LD}\left(35^{\circ} 37^{\prime} 5.75^{\prime \prime} \mathrm{N}, 106^{\circ} 07^{\prime} 8.27^{\prime \prime} \mathrm{E}\right)$ in Ningxia Hui Autonomous Region in the northwest of China 


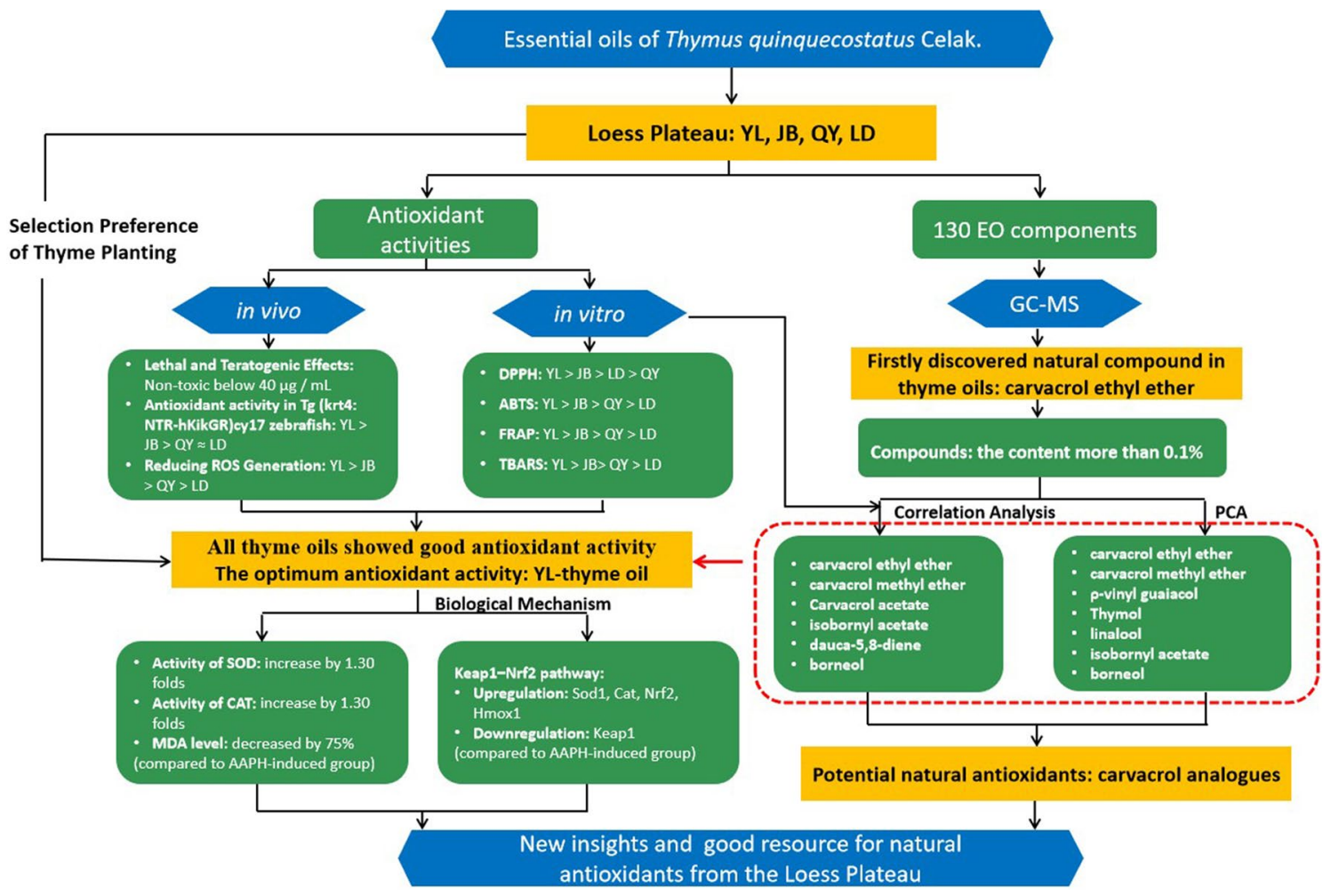

Figure 2. Technical route.

in the month of August. They were carefully identified by Dr. Shengjun Ma (Beijing University of Chinese Medicine). Those samples were separately dried in shade and deposited at the Lab of Engineering Research Center of GAP for Chinese Crude Drugs, Ministry of Education, Beijing University of Chinese Medicine.

Extraction of Eos. Dry samples $(300 \mathrm{~g})$ of thyme from the four producing areas were severally soaked in deionized water at room temperature about $25^{\circ} \mathrm{C}$ to stand overnight, and then were subjected to hydrodistillation in a modified clevenger-type apparatus for $10 \mathrm{~h}$. The obtained EOs were extracted with $n$-hexane. Subsequently, the extracts were exsiccated by anhydrous sodium sulphate and stored in a stopper vials at $4{ }^{\circ} \mathrm{C}$ in a refrigerator until the time of analysis.

GC-MS analysis. EOs were analyzed by an HP 5890 gas chromatograph (GC) using an HP 5973 mass selective detector (Finnigan Trace-MS 2000, USA) with the electron ionization mode (70 eV). The capillary column was a HP-5MS ( $5 \%$ phenyl methyl siloxane, $30 \mathrm{~m} \times 0.25 \mathrm{~mm}$ i.d., $0.25 \mu \mathrm{m}$ film thickness). The temperature of the inlet and detector, injection volume and split ratio were set to $260^{\circ} \mathrm{C}, 260^{\circ} \mathrm{C}, 1 \mu \mathrm{L}$ (TBME solution), $40: 1$, respectively. The oven temperature started at $50^{\circ} \mathrm{C}$, ramped to $100^{\circ} \mathrm{C}$ at a rate of $5{ }^{\circ} \mathrm{C} / \mathrm{min}$, ramped to $150{ }^{\circ} \mathrm{C}$ at a rate of $3{ }^{\circ} \mathrm{C} / \mathrm{min}$, and ramped to $250^{\circ} \mathrm{C}$ at a rate of $5^{\circ} \mathrm{C} / \mathrm{min}$, then held at $250^{\circ} \mathrm{C}$ for $30 \mathrm{~min}$. Helium (99.999\%) carrier gas was kept with a constant flow of $1.2 \mathrm{~mL} / \mathrm{min}$. A standard n-alkane mixture $\left(\mathrm{C}_{6}-\mathrm{C}_{24}\right)$ was also analyzed using the above conditions to determine the retention index (RI).

Identification of compounds. The thyme oils were identified by the retention indices (RI), relative to the series of alkanes $\left(\mathrm{C}_{6}-\mathrm{C}_{24}\right)$ at the same chromatographic conditions, referring to the Van Den Dool method ${ }^{11}$. The data were analyzed by the Xcalibur 1.1 software, compared with NIST/EPA/NIH database (1998, version 1.6) and several references" ${ }^{12,13}$. The book "Identification of Essential Oils Components by Gas Chromatogrtaphy/ Mass Spectrometry, 4th edition" (Robert P. Adams, $\mathrm{PhD}$ ) equally played a vital role in identifying the individual compounds.

DPPH assay. The DPPH test was carried out as described before ${ }^{14} .0 .1 \mathrm{~mL}$ thyme oils at various concentrations of $(0.02-5.67 \mathrm{mg} / \mathrm{mL})$ were added in $0.1 \mathrm{~mL}$ ethanol solution of DPPH $(0.001 \mathrm{mg} / \mathrm{mL})$ acquired from SigmaAldrich (Saint Louis, MO, USA). The absorbance of each solution was measured at $517 \mathrm{~nm}$, with ethanol being a blank. Ascorbic acid was used as a positive control. Simple regression analysis was used to derive the $\mathrm{IC}_{50}$ value.

ABTS assay. The antioxidant activity of the samples was determined by using the method described previously ${ }^{15}$. An ABTS stock solution was prepared by dissolving ABTS (Sigma-Aldrich) (7 mM) in water. An ABTS radical cation $\left(\mathrm{ABTS}^{+}\right)$solution was then prepared by mixing the ABTS stock solution with potassium persulfate solution $(2 \mathrm{mM})$ in equal quantities and in the dark at room temperature. The ABTS ${ }^{+}$solution was 
diluted with PBS (10 mM, pH 7.4) to an absorbance of $0.70 \pm 0.02$ at $734 \mathrm{~nm}$ and stabilized at $30^{\circ} \mathrm{C}$. Next, $0.1 \mathrm{~mL}$ thyme oils at different concentrations $(0.02-2.32 \mathrm{mg} / \mathrm{mL})$ were mixed with $0.1 \mathrm{~mL}$ dilution $\mathrm{ABTS}^{\bullet+}$ solution with ethanol; after $10 \mathrm{~min}$, the absorbance of the mixture was measured at $734 \mathrm{~nm}$ in the dark at room temperature. As a positive control, ascorbic acid was chosen to be employed. Simple regression analysis was used to derive the $\mathrm{IC}_{50}$ value.

FRAP assay. FRAP activity was estimated by the assay described by Benzie and Strain $(1996)^{16} .5 \mathrm{~mL}$ of freshly prepared FRAP reagent and $20 \mathrm{uL}$ thyme oils $(2.32-16.87 \mathrm{mg} / \mathrm{mL})$ were mixed and the resulting solution was vortexed and then incubated at room temperature for $70 \mathrm{~min}$. After the incubation, the absorbance was measured at $594 \mathrm{~nm}$. Ferrous sulfate solutions $\left(\mathrm{FeSO}_{4}\right)\left(1-33 \mathrm{mmol} \cdot \mathrm{L}^{-1}\right)$ were used to obtain the standard curve and trolox $(0.975 \mathrm{mg} / \mathrm{mL})$ was used as the positive control. The results were expressed as mmol of ferrous sulfate equivalents per gram per liter of thyme oils. The ferric reducing activity of all samples was expressed as $\mathrm{FeSO}_{4}$ equivalent $\left(\mathrm{mmol} \cdot \mathrm{L}^{-1} \cdot \mathrm{g}^{-1} \mathrm{DW}\right)$.

Measurement of lipid peroxidation by thiobarbituric acid reactive substances (TBARS) assay. The TBARS assay is widely used to measure lipid oxidation and antioxidant activity in food and physiological systems. Modified TBARS were used to measure the lipid peroxide using mouse liver homogenates as lipid-rich media ${ }^{17}$. Briefly, thiobarbituric acid reacts with malondialdehyde (MDA) to form a diadduct, a pink chromogen, which can be detected spectrophotometrically at $535 \mathrm{~nm}$. $0.2 \mathrm{~mL}$ thyme oils at different concentrations $(0.18-1.82 \mathrm{mg} / \mathrm{mL}$ ) were mixed with $10 \%$ liver homogenate (each $100 \mathrm{~mL}$ homogenate solution contains $10.0 \mathrm{~g}$ mouse liver), then $0.1 \mathrm{~mL}$ of $\mathrm{FeSO}_{4} \cdot 7 \mathrm{H}_{2} \mathrm{O}(5 \mathrm{mM})$ and $0.1 \mathrm{~mL} \mathrm{H}_{2} \mathrm{O}_{2}(100 \mathrm{mM})$ were added to initiate lipid peroxidation. After incubation for $60 \mathrm{~min}$ at $37^{\circ} \mathrm{C}$, the reaction was stopped by addition of $0.3 \mathrm{~mL} 0.68 \%$ thiobarbituric acid in TCA- $\mathrm{HCl}(16.8 \% \mathrm{w} / \mathrm{v}$ trichloroacetic acid in $0.125 \mathrm{~N} \mathrm{HCl})$. The reaction mixtures were heated for $60 \mathrm{~min}$ at $95^{\circ} \mathrm{C}$. The samples were cooled and centrifuged, and the absorbance of the supernatants was measured at $535 \mathrm{~nm}$. Simple regression analysis was used to derive the $\mathrm{IC}_{50}$ value. The results were compared to that of ascorbic acid employed as the reference.

Zebrafish maintenance. The adult zebrafish AB strain and Tg (krt4:NTR-hKikGR ${ }^{\mathrm{cy} 17}$ transgenic zebrafish lines were obtained from Drug Screening Platform of Shandong Academy of Sciences (Jinan, Shandong, China). The adult zebrafish used in this study were reared at $28 \pm 0.5^{\circ} \mathrm{C}$ with a $14: 10 \mathrm{~h}$ light-dark cycle in an automatic zebrafish housing system (ESEN, Beijing, China) with fish water $(5 \mathrm{mM} \mathrm{NaCl}, 0.17 \mathrm{mM} \mathrm{KCl}, 0.4 \mathrm{mM} \mathrm{CaCl}$, and $0.16 \mathrm{mM} \mathrm{MgSO}_{4}$ ). Embryos were collected and maintained in the zebrafish spawning box after natural spawning induced by light in the morning and then maintained in a light incubator at $28^{\circ} \mathrm{C}$ until $24 \mathrm{~h}$ post fertilization (hpf). At the end of the experiments, all zebrafish were euthanized with an overdose of tricaine $(200 \mathrm{mg} / \mathrm{L})$.

Lethal and teratogenic assay. As depicted in previous research ${ }^{18}$, normal developing embryos were selected under a stereomicroscope (SZX16, Olympus, Tokyo, Japan) at $24 \mathrm{hpf}$ and were randomly tranferred to 24-well plates at a density of 15 per well. Thyme oils were diluted with fish water to different concentrations ( 1 , $5,10,20,40 \mu \mathrm{g} / \mathrm{mL}$ ) in each well to a final volume of $2 \mathrm{~mL}$. Mortality rates were investigated till $48 \mathrm{hpf}$. Also, morphological changes of craniofacial features, brain, kidney, yolk sac, swim bladder, pericardium and body shape were monitored under the stereomicroscope. And the value of $10 \%$ lethal concentration $\left(\mathrm{LC}_{10}\right)$ and $1 \%$ lethal concentration $\left(\mathrm{LC}_{1}\right)$ were calculated. In subsequent experiments, thyme oils were used at concentrations of $1 / 3 \mathrm{LC}_{1}, \mathrm{LC}_{1}, \mathrm{LC}_{10}$.

Antioxidant activity in Tg (krt4: NTR-hKikGR) cy17 zebrafish larvae. 24-hpf Tg (krt4: NTRhKikGR $)^{\text {cy17 }}$ zebrafish (15 embryos/well) were added to 24 -well plates, and incubated with or without metronidazole (MTZ) ( $5 \mathrm{mM}$ ) (Sigma-Aldrich). Thyme oils were diluted with fish water to different concentrations $(5,10$ and $20 \mu \mathrm{g} / \mathrm{mL})$ to a final volume of $2 \mathrm{~mL}$. After $24 \mathrm{~h}$ of incubation, zebrafish larvae were anesthetized using $0.16 \%$ tricaine, and then fluorescence was detected by FSX100 Bio Imaging Navigator Equipment. N-acetyl-1cysteine (L-NAC) $(0.2 \mathrm{mM})$ was used as a positive control. L-NAC is a classical antioxidant that can reduce the damage to cells caused by oxidative stress and has been widely used as an antioxidant positive control in vivo ${ }^{19,20}$. The relative antioxidant capacity of the thyme oils can be determined by counting the number of fluorescence spots using Image-Pro Plus software. A fixed square region $(18.00 \mathrm{~cm} \times 6.00 \mathrm{~cm})$ of the images on zebrafish body was selected and calculated the number of fluorescence.

Measurement of intracellular ROS production in AB zebrafish larvae. The dichloro-dihydrofluorescein diacetate (DCFH-DA) method was used to quantify intracellular ROS levels ${ }^{21}$. All treatment solutions were diluted to different concentrations using fish water. 24-hpf AB zebrafish (15 embryos/well) were added to 24 -well plates, and incubated with or without thyme oils $(5,10$ and $20 \mu \mathrm{g} / \mathrm{mL})$ to a final volume of $2 \mathrm{~mL}$ for $1 \mathrm{~h}$. Then, 2,2-Azobis (2-amidinopropane) dihydrochloride (AAPH) (12 mM) was added to incubate for $24 \mathrm{~h}$. L-NAC $(0.2 \mathrm{mM})$ was used as a positive control. A ROS kit (Nanjing Jiancheng Bioengineering Institute, Nanjing, China) was used for analyzing generation of ROS in larvae at $48 \mathrm{hpf}$. The treatment groups were treated with $30 \mu \mathrm{M}$ DCFH-DA and incubated in the dark at $28 \pm 0.5^{\circ} \mathrm{C}$ for $40 \mathrm{~min}$. The zebrafish larvae were then washed with fish water three times and were observed using a fluorescence microscope (SZX16, Olympus, Tokyo, Japan). Fluorescence intensity of each zebrafish larva was determined using the Image-Pro Plus software. 


\begin{tabular}{|l|l|l|l|}
\hline No & Gene symbol & Forward primer $\left(\mathbf{5}^{\prime} \mathbf{-} \mathbf{3}^{\prime}\right)$ & Reverse primer $\left(\mathbf{5}^{\prime} \mathbf{-} \mathbf{3}^{\prime} \mathbf{)}\right.$ \\
\hline 1 & Sod 1 & ATGGTGAACAAGGCCGTTTG & CATGAGGGTTGAAGTGCGGA \\
\hline 2 & Cat & ACTACAAGACTAATCAGGGCATTAAGAA & CCCACAGGAATCAGAGGGAACT \\
\hline 3 & Keap1 & CCAACGGCATAGAGGTAGTTAT & CCTGTATGTGGTAGGAGGGTT \\
\hline 4 & Nrf2 & TTGTCTTTGGTGAACGGAGGT & CTCGGAGGAGATGGAAGGAAG \\
\hline 5 & Hmox 1 & ATGCCCTTGTTTCCAGTCAGC & GGACTTGGAGCACTTCTTCGG \\
\hline
\end{tabular}

Table 1. The sequences of primer pairs used in real-time quantitative PCR assay.

Assessment of antioxidative enzyme and lipid peroxidation activities in $A B$ zebrafish larvae. The test was carried out as described before ${ }^{18}$. Briefly, 24-hpf AB zebrafish were transferred into sixwell plates (100 larvae/3 well/group), and incubated with or without AAPH (12 mM) and YL-thyme oils (5, 10 and $20 \mu \mathrm{g} / \mathrm{mL})$ to a final volume of $5 \mathrm{~mL}$. L-NAC $(0.2 \mathrm{mM})$ was used as a positive control. All treatment solutions were diluted to final different concentrations using fish water. Larvae in each group were pooled together and homogenized on ice with $500 \mu \mathrm{L}$ ice-cold physiological saline at $48 \mathrm{hpf}$. The supernatants were collected for analysis of antioxidative enzyme and lipid peroxidation activities after centrifugation at 3,500 rpm for $15 \mathrm{~min}$ at $4{ }^{\circ} \mathrm{C}$. SOD, CAT activity and MDA levels were assessed using commercial kits (Nanjing Jiancheng Bioengineering Institute) in accordance with the manufacturer's protocols. SOD and CAT activity were expressed as unit per milligram protein and MDA levels were showed as nmol per milligram protein. And the protein content was determined using the bicinchoninic acid method ${ }^{22}$.

Quantitative real-time polymerase chain reaction (qRT-PCR) assay in AB zebrafish larvae. $\quad 24-$ hpf AB zebrafish were transferred into six-well plates (30 embryos/well), and incubated with or without AAPH $(12 \mathrm{mM})$ and YL-thyme oils $(5,10$ and $20 \mu \mathrm{g} / \mathrm{mL})$ to a final volume of $5 \mathrm{~mL}$. L-NAC $(0.2 \mathrm{mM})$ was used as a positive control. All treatment solutions were diluted to final different concentrations using fish water. Total zebrafish RNA was extracted from 30 larvae (48 hpf) using the TRIzol reagent (Invitrogen, Waltham, USA) following the manufacturer's instructions. RNA concentrations and quality were evaluated on the basis of $\mathrm{OD}_{260} /$ $\mathrm{OD}_{280}$ ratio. Then the synthesis of cDNA was carried out by using the HiScript II Q RT SuperMix (Vazyme, Nanjing, China), and RT-PCR was done by using a RT-PCR system (Biorad, CA, USA) using the SYBR Green mix (Takara, Dalian, China). Thermal cycling was set at $95^{\circ} \mathrm{C}$ for $5 \mathrm{~s}$ and $60^{\circ} \mathrm{C}$ for $30 \mathrm{~s}$ with 40 cycles. Transcription of target genes was calculated using the $2^{-\Delta \Delta \mathrm{Ct}}$ method. $\beta$-actin was chosen as the house-keeping gene. The primer sequences of the genes that were detected are shown in Table 1 .

Statistical analysis. All the assays were conducted in triplicate and results were expressed as mean values \pm standard deviation (SD). Analysis of variance (ANOVA) test was performed to check significant differences. Comparison between the groups was performed using Student-Newman-Keuls (SNK). Differences from controls were considered significant when $p$ was less than 0.05 or 0.01 . Removal of the compounds with concentrations less than $0.1 \%$ had no effect on the overall analysis. Therefore, the thyme volatile constituents with the content more than $0.1 \%$ were evaluated using Principal Component Analysis (PCA) and Hierarchical Clustering Analysis (HCA), which could highlight the similarity and dissimilarity of the EO constituents and expound the active ingredients of thyme oils. Correlation analyses were performed by using a two-tailed Pearson's correlation test. All statistical analyses were carried out by using OriginPro 2017 and GraphPad Prism (version 6.01).

\section{Results and discussions}

Chemical compositions of thyme oils. The aerial parts of T. quinquecostatus were hydrodistilled and produced a yellow EOs with characteristic odor, with the yield of $4.67 \mathrm{~mL} / \mathrm{kg}(\mathrm{YL}), 2.33 \mathrm{~mL} / \mathrm{kg}(\mathrm{JB}), 5.00 \mathrm{~mL} /$ $\mathrm{kg}(\mathrm{QY})$ and $2.67 \mathrm{~mL} / \mathrm{kg}(\mathrm{LD})$. Total ion chromatograms (TICs) given by GC-MS of the thyme oils was shown in Fig. 3 (YL-thyme oil (Fig. 3a), JB-thyme oil (Fig. 3b), QY-thyme oil (Fig. 3c) and LD-thyme oil (Fig. 3d)). And the retention indices (RI) and percentages of thyme oil chemical compositions were listed in Table 2. Monoterpenes are the most frequent metabolites of the thyme oils, including hydrocarbon monoterpenes (1.29$29.88 \%)$, oxygenated monoterpenes (17.09-27.89\%) and phenolic monoterpenes (0.38-16.32\%).

The common compounds of thyme oil from the four regions. Among the EO components with the content greater than $0.1 \%, 1,8$-cineole, linalool, terpinen-4-ol, $\gamma$-terpinene, borneol, $\beta$-bisabolene and $\alpha$-pinene were the common ingredients in the thyme oils from the four regions.

The content of 1,8-cineole (1.84\%-10.16\%), which is the highest in the QY-thyme oil (10.16\%), was similar to that from T. vulgaris $\mathrm{L}$. with a percentage of $9.8 \%{ }^{23}$. Furthermore, 1,8 -cineole has been widely used in perfume industry and pharmaceutical industry ${ }^{24}$. Compared to the essential oil of thyme (T. vulgaris L. and T. zygis L.) in International Standard (ISO 19,817: 2017), the percentage of linalool (1.22\%-12.80\%) and terpinen4-ol $(1.03 \%-10.56 \%)$ in this study were far in excess of this standard. Meanwhile, the content of $\gamma$-terpinene $(0.15 \%-11.11 \%)$ and $\alpha$-pinene $(0.07 \%-1.04 \%)$ were in accordance with International Standard (ISO 19,817: 2017). 

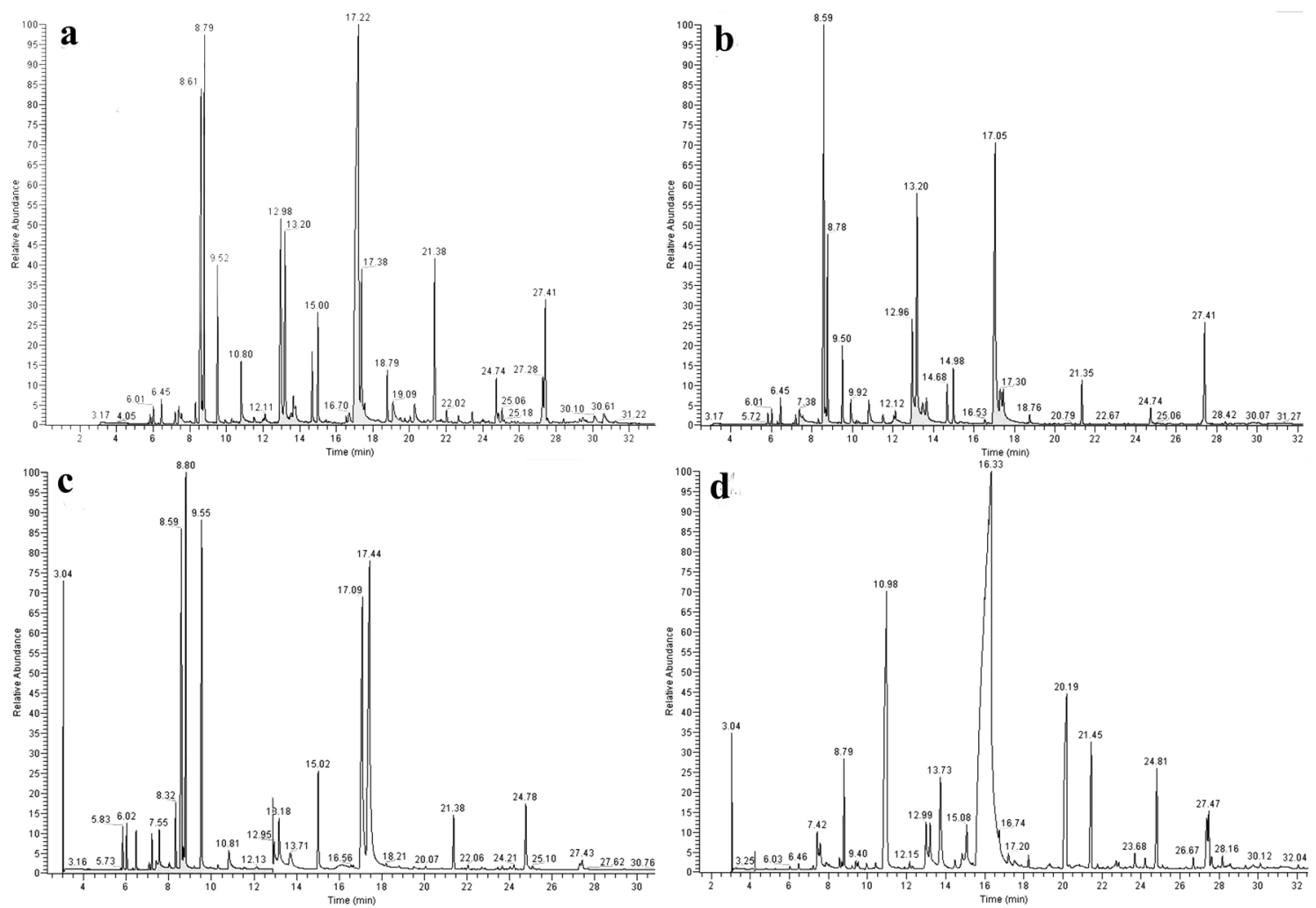

Figure 3. Total ion chromatograms (TICs) given by GC-MS of the YL-thyme oil (a), JB-thyme oil (b), QY-thyme oil (c) and LD-thyme oil (d).

The borneol was observed in amounts of $6.50 \%$ in YL-thyme oil, similar to that of JB-thyme oil (5.61\%). It showed the content of $1.52 \%$ in the QY-thyme oil, similar to that of LD-thyme oil (1.38\%). Nowadays, it is a famous compound in prescription for cardiovascular and cerebrovascular diseases ${ }^{25}$. Additionally, $\beta$-bisabolene is a popular resource for the synthesis of many natural products and it has been approved as a food additive in Europe $^{26}$. The content of $\beta$-bisabolene was the highest in QY-thyme oil (2.84\%), followed by that of LD-thyme oil (2.36\%), JB-thyme oil (1.03\%) and YL-thyme oil (1.12\%).

The individual thyme oil composition from the four regions. Notably, the carvacrol ethyl ether was firstly discovered as a new natural product and its amount is significant in YL-thyme oil (31.80\%) and JB-thyme oil (23.32\%). It is the pale yellow clear oily liquid and has spicy odor. Carvacrol ethyl ether has been used as a synthetic flavoring substance with no safety concern at current levels of intake evaluated by the Joint FAO/WHO Expert Committee on Food Additives (JECFA). The interesting component $\rho$-vinyl guaiacol was indicated with the highest content in QY-thyme oil (23.55\%), followed by that of YL-thyme oil (3.97\%). Vinyl guaiacol appeared as colorless or canary yellow liquid that mostly found in the volatile from corn alcohol fermentation and it is a high value-added product widely used in cosmetic, pharmaceutical and chemical industries ${ }^{27}$. Additionally, JB-thyme oil displayed the highest content of terpinen-4-ol (10.56\%) while 4.96\% in YL-thyme oil. Thymol, the isomeric of carvacrol, was observed as a dominant compound (16.32\%) in QY-thyme oil. It exhibited significantly antifungal, antibacterial and anti-inflammatory properties, together with anticonvulsant and antiepileptogenic activities as adjuvant to $\mathrm{AEDs}^{28}$. Finally, there were two components that had not been identified. One compound $(\mathrm{RT}=16.32, \mathrm{RI}=1,277.300)$ composed $54 \%$ of the total volatile ingredients in LD-thyme oil. And another one $(\mathrm{RT}=8.6, \mathrm{RI}=1,027.931)$ accounted for $10.16 \%$ of the volatile composition in YL-thyme oil.

Multivariate analysis. The content of compounds greater than $0.1 \%$ of the thyme oils had been used for chemometric analysis. Both the chemical composition and their content of the total EOs from the four regions were obviously different. It was interesting that the thyme oils from JB and YL were in great similarity. It might result from the close distance between JB and YL, as well as the similar growing conditions such as climate, strength of illumination, humidity of soil and air etc. Thus, growing condition might be the main influencing factor to the chemo-variation in the thyme oils produced from the four regions.

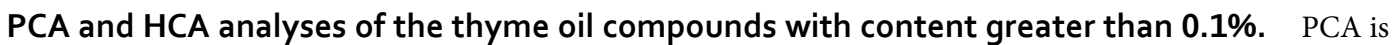
an unsupervised multivariate method and transforms the original set of variables to a new set of uncorrelated variables called principal components (PCs). By plotting the PCA scores, it is possible to visually assess similarities between samples and determine whether samples can be grouped or not ${ }^{29}$. In present study, score plots were created in order to assess clustering tendency of samples, and three significant principal components 


\begin{tabular}{|c|c|c|c|c|c|c|}
\hline \multirow[b]{2}{*}{ No } & \multirow[b]{2}{*}{ Name } & \multirow[b]{2}{*}{ RI } & \multicolumn{4}{|c|}{ Samples } \\
\hline & & & QY & LD & JB & YL \\
\hline \multicolumn{7}{|c|}{ Those composition possessing more than $0.1 \%$} \\
\hline 1 & Artemisia triene & 923 & - & - & - & 0.20 \\
\hline 2 & a-Thujene & 926 & 1.01 & - & 0.36 & - \\
\hline 3 & a-Pinene & 933 & 1.04 & 0.07 & 0.46 & 0.38 \\
\hline 4 & a-Fenchene & 945 & 0.89 & 0.12 & - & - \\
\hline 5 & Camphene & 949 & - & - & 0.81 & 0.50 \\
\hline 6 & Artemiseole & 973 & 0.18 & - & - & - \\
\hline 7 & 1-Octen-3-ol & 974 & - & - & 1.15 & \\
\hline 8 & $\beta$-Pinene & 978 & 0.84 & $\operatorname{tr}$ & 0.30 & 0.25 \\
\hline 9 & 3-Octanone & 979 & - & 0.84 & - & 0.59 \\
\hline 10 & 1-Decene & & 0.41 & - & - & - \\
\hline 11 & 6-Methyl-5-hepten-2-one & 981 & - & 0.26 & - & - \\
\hline 12 & 3-Octanol & 988 & - & 0.12 & & $\operatorname{tr}$ \\
\hline 13 & Myrcene & 990 & - & 0.64 & 0.54 & 0.27 \\
\hline 14 & Methyl-pentanoatel(2-Hydroxy-3-methyl-) & 991 & 1.20 & - & - & - \\
\hline 15 & iso-Sylvestrene & 1007 & 0.13 & - & - & - \\
\hline 16 & a-Terpinne & 1014 & - & - & - & 0.46 \\
\hline 17 & $a$-Terpinene & 1017 & 1.62 & - & 0.20 & - \\
\hline 18 & $\rho$-Cymene & 1020 & - & 0.18 & 19.2 & - \\
\hline 19 & $o$-Cymene & 1022 & 12.10 & - & - & - \\
\hline 20 & (Z)- $\beta$-Ocimene & 1031 & 0.60 & - & - & - \\
\hline 21 & Limonene & 1024 & - & 0.13 & 0.69 & 0.40 \\
\hline 22 & 1,8-Cineole & 1026 & 10.16 & 1.84 & 5.22 & 7.23 \\
\hline 23 & Prenyl isobutyrate & 1048 & - & 0.23 & - & - \\
\hline 24 & $\gamma$-Terpinene & 1054 & 11.11 & 0.15 & 2.73 & 3.03 \\
\hline 25 & cis-Sabinene hydrate & 1065 & - & - & 1.28 & - \\
\hline 26 & cis-Linalool oxide & 1067 & - & 0.13 & - & 0.08 \\
\hline 27 & Terpinolene & 1086 & 0.13 & - & 0.10 & 0.21 \\
\hline 28 & Linalool & 1095 & 1.22 & 12.80 & 1.92 & 1.80 \\
\hline 29 & cis- $\rho$-Menth-2-en-1-ol & 1118 & - & - & 0.58 & - \\
\hline 30 & Camphor & 1141 & 0.11 & 0.12 & 0.63 & - \\
\hline 31 & trans- $\rho$-Menth-2-en-1-ol & 1136 & - & - & 0.42 & 0.20 \\
\hline 32 & (Z)-Tagetone & 1147 & - & - & - & 0.33 \\
\hline 33 & Borneol & 1165 & 1.52 & 1.38 & 5.61 & 6.50 \\
\hline 34 & Terpinen-4-ol & 1174 & 2.60 & 1.03 & 10.56 & 4.96 \\
\hline 35 & a-Terpineol & 1186 & 1.06 & - & 1.26 & - \\
\hline 36 & $\gamma$-Terpineol & 1199 & - & 3.04 & - & 0.68 \\
\hline 37 & $\rho$-Cymen-8-ol & 1179 & - & - & 0.94 & 0.32 \\
\hline 38 & Thymol methyl ether & 1233 & 3.38 & - & 1.67 & 1.63 \\
\hline 39 & Neral & 1235 & - & 1.35 & - & - \\
\hline 40 & Carvacrol methyl ether & 1241 & - & - & 2.25 & 2.48 \\
\hline 41 & Isobornyl acetate & 1283 & 0.07 & - & 0.27 & 0.64 \\
\hline 42 & Thymol & 1288 & 16.32 & - & 0.10 & - \\
\hline 43 & Bornyl acetate & 1289 & 0.08 & 0.22 & - & - \\
\hline 44 & Carvacrol ethyl ether & 1297 & - & - & 23.32 & 31.80 \\
\hline 45 & Carvacrol & 1298 & - & 0.30 & 2.89 & $\operatorname{tr}$ \\
\hline 46 & $\rho$-vinyl guaiacol & 1307 & 23.55 & - & - & 3.97 \\
\hline 47 & Dihydro citronellol acetate & 1319 & - & - & - & 0.27 \\
\hline 48 & Thymol acetate & 1345 & 0.09 & - & 0.48 & - \\
\hline 49 & 4'-Methoxy-Acetophenone & 1346 & - & - & - & 1.32 \\
\hline 50 & Eugenol & 1354 & - & 0.08 & - & 1.24 \\
\hline 51 & Neryl acetate & 1361 & - & 0.18 & - & - \\
\hline 52 & Carvacrol acetate & 1370 & - & - & tr & 0.15 \\
\hline 53 & a-Ylangene & 1372 & $\operatorname{tr}$ & - & - & 0.10 \\
\hline Со & & & & & & \\
\hline
\end{tabular}




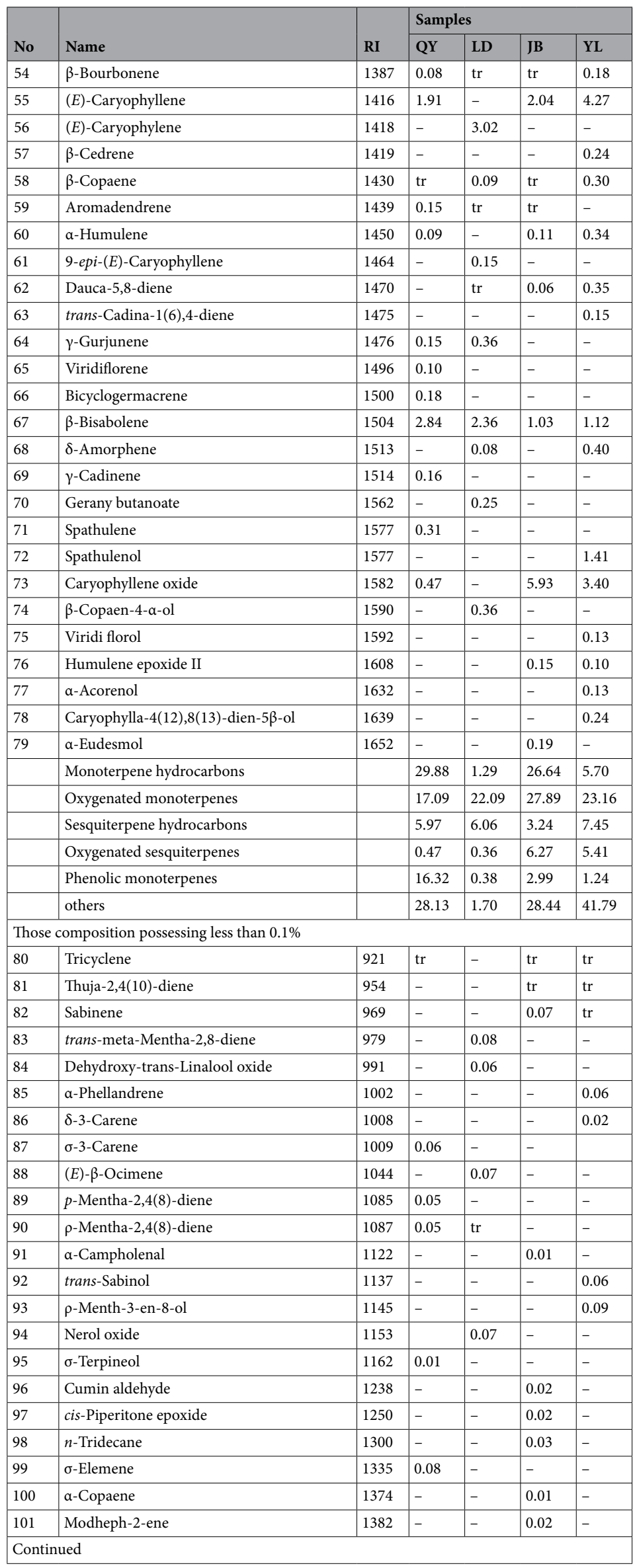




\begin{tabular}{|c|c|c|c|c|c|c|}
\hline \multirow[b]{2}{*}{ No } & \multirow[b]{2}{*}{ Name } & \multirow[b]{2}{*}{ RI } & \multicolumn{4}{|c|}{ Samples } \\
\hline & & & QY & LD & JB & YL \\
\hline 102 & $\beta$-Elemene & 1386 & - & 0.07 & $\operatorname{tr}$ & - \\
\hline 103 & $\alpha$-Isocomene & 1387 & - & - & 0.05 & - \\
\hline 104 & $\beta$-Isocomene & 1407 & - & - & 0.03 & - \\
\hline 105 & $\alpha$-trans-Bergamotene & 1430 & $\operatorname{tr}$ & $\operatorname{tr}$ & $\operatorname{tr}$ & - \\
\hline 106 & allo-Aromadendrene & 1458 & $\operatorname{tr}$ & $\operatorname{tr}$ & - & - \\
\hline 107 & cis-Cadina-1(16),4-diene & 1463 & - & 0.02 & - & - \\
\hline 108 & cis-Muurola-4(14),5-diene & 1465 & - & - & 0.05 & - \\
\hline 109 & 4,5-di-epi-Aristolochene & 1471 & - & - & - & 0.02 \\
\hline 110 & $\gamma$-Muurolene & 1478 & - & - & - & 0.06 \\
\hline 111 & ar-Curcumene & 1479 & - & - & 0.03 & - \\
\hline 112 & $\beta$-Selinene & 1490 & - & - & $\operatorname{tr}$ & $\operatorname{tr}$ \\
\hline 113 & $\gamma$-Amorphene & 1494 & - & 0.03 & - & - \\
\hline 114 & Pseudowiddrene & 1498 & 0.02 & - & - & - \\
\hline 115 & cis- $\beta$-Guaiene & 1492 & - & - & 0.02 & - \\
\hline 116 & $n$-Pentadecane & 1500 & - & - & 0.03 & - \\
\hline 117 & $\beta$-Sesquiphellandrene & 1521 & - & 0.03 & - & - \\
\hline 118 & (E)-iso- $\gamma$-Bisabolene & 1528 & - & 0.02 & - & - \\
\hline 119 & trans-Cadina-1,4-diene & 1533 & $\operatorname{tr}$ & - & - & 0.05 \\
\hline 120 & a-Cadinene & 1537 & $\operatorname{tr}$ & - & - & 0.07 \\
\hline 121 & a-Calacorene & 1544 & - & - & 0.01 & 0.05 \\
\hline 122 & trans-Danca-4(11),7-diene & 1556 & - & 0.02 & - & - \\
\hline 123 & $\beta$-Calacorene & 1564 & - & - & - & 0.09 \\
\hline 124 & Guaiol & 1600 & - & 0.07 & - & - \\
\hline 125 & Junenol & 1618 & - & - & - & 0.04 \\
\hline 126 & 1-epi-Cubenol & 1627 & - & - & - & 0.07 \\
\hline 127 & Eremoligenol & 1628 & - & - & 0.07 & - \\
\hline 128 & epi-a-Cadinol & 1638 & - & - & - & 0.07 \\
\hline 129 & epi-a-Muurolol & 1640 & - & - & - & 0.04 \\
\hline 130 & a-Cadinol & 1653 & 0.01 & - & - & - \\
\hline
\end{tabular}

Table 2. Chemical constituents of the thyme oil in the four regions. a: “-” means the compound is not identified; b: "tr" represent the percent of compound is lower than $0.05 \%$; c: "RI" represent the Retention indices on the DB-5 column.

(PCs) explained 40.56\% (PC1), 33.63\% (PC2) and 25.80\% (PC3) of total variance (Fig. 4a). As shown in Fig. 4c, YL-thyme oil had relatively high scores on PC1, while the QY-thyme oil with the mostly negative PC1 scores. On PC2, the LD-thyme oils had quite negative scores.

The loading vectors responsible for the separations were distributed as Fig. 4b: loading 33, 41, 40 and 44, corresponding to compounds borneol, isobornyl acetate, carvacrol methyl ether and carvacrol ethyl ether, respectively. They were principally responsible for the discrimination of the YL-thyme oil on the PC1. The vectors 28 and 36, represented by linalool and $\gamma$-terpineol, were principally involved in the discrimination on the LD-thyme oil. And the vector 42 (thymol) and 46 ( $\rho$-vinyl guaiacol) were strongly featured in separating QY-thyme oil with high negative scores on the PC1.

As with PCA, HCA is also an unsupervised multivariate method, which evaluates the samples by taking account of the chosen distance between samples and group average method was adopted when Euclidean Distance was applied as the measurement ${ }^{30}$. Using $D_{\text {linkage }}=22.9$ as a criterion for the selection of the number of groups, three clusters were obtained: Cluster I (QY-thyme oil), Cluster II (LD-thyme oil) and Cluster III (JB-thyme oil and YL-thyme oil) (Fig. 4d) and the obtained clusters are in complete agreement with the groups previously defined by PCA.

In vitro antioxidant activities of thyme oils from the four regions. Phytochemicals are known to have a complex nature hence no single assay will accurately reflect all of the radical sources or all antioxidants in a mixed or complex system ${ }^{31}$. In this study, the in vitro antioxidant activity of thyme oils was evaluated using the DPPH, ABTS, FRAP and TBARS methods.

DPPH assay. DPPH molecule that contains a stable free radical has been widely used to evaluate the radical scavenging ability of antioxidants. Comparing with the standard antioxidant ascorbic acid $\left(\mathrm{IC}_{50}=0.026 \mathrm{mg} / \mathrm{mL}\right)$, the YL-thyme oil possessed the highest antioxidant activity $\left(\mathrm{IC}_{50}=0.512 \mathrm{mg} / \mathrm{mL}\right)$, followed by $0.530 \mathrm{mg} / \mathrm{mL}$ in 


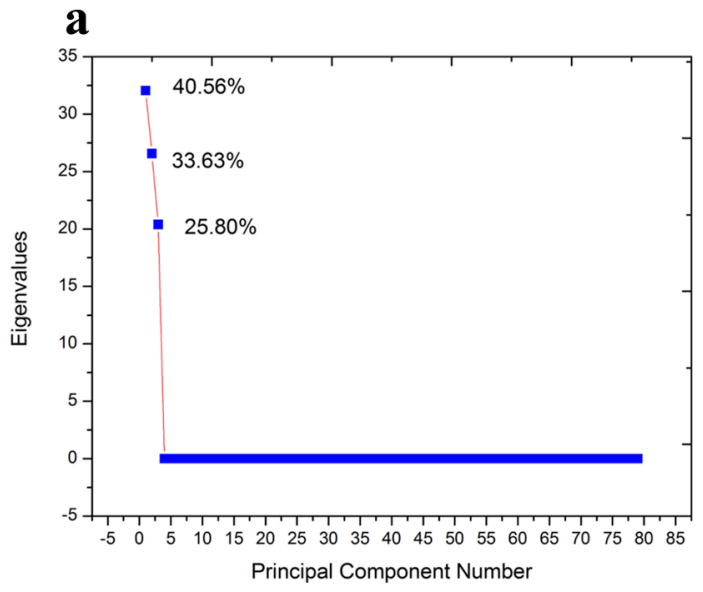

c

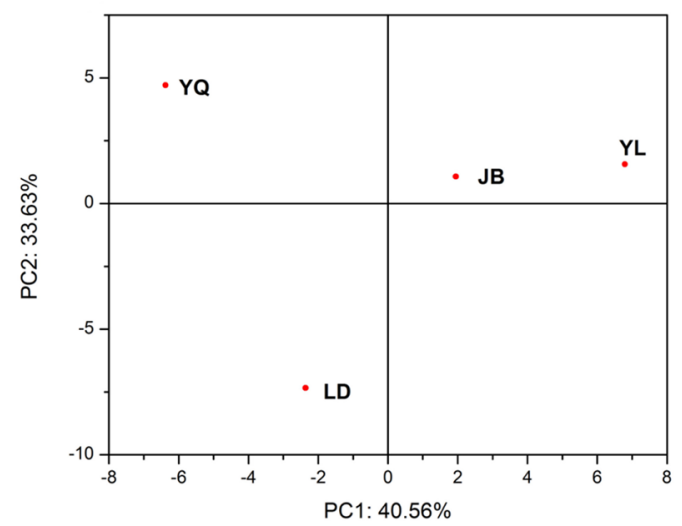

b

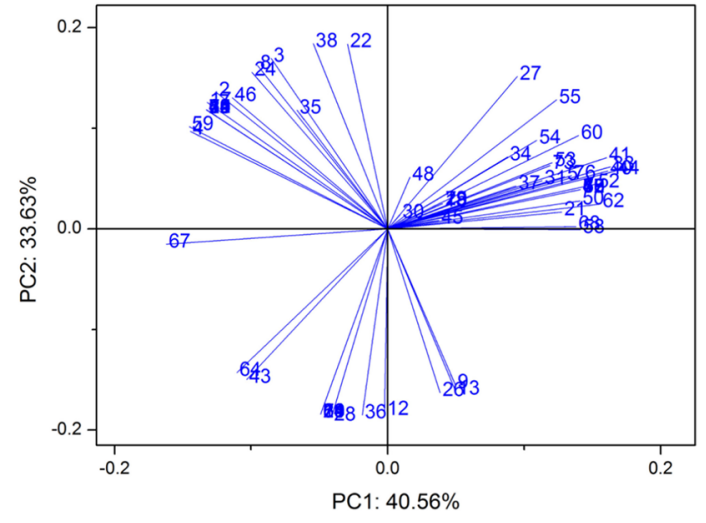

d

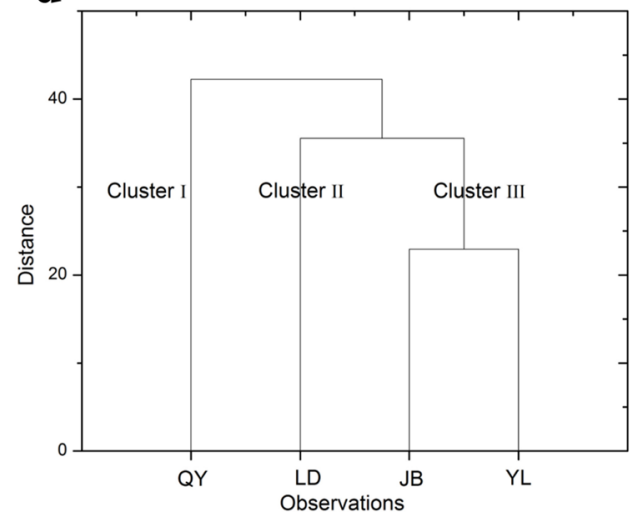

Figure 4. PCA and HCA plots of the thyme oil compositions from the four regions: eigenvalues of the correlation matrix (a); the loading plot of active chemical compounds (b); the score plot of the tested thyme oil (c); the corresponding dendogram (d).

JB-thyme oil, $0.905 \mathrm{mg} / \mathrm{mL}$ in LD-thyme oil and $0.931 \mathrm{mg} / \mathrm{mL}$ in QY-thyme oil (Fig. 5a). The results indicate that YL-thyme oil have better potential as radical scavenger antioxidants than other essential oils.

ABTS assay. ABTS method is more reliable due to solubility of the ABTS reagent in both aqueous and organic solvents and rapid reaction with lipophilic as well as hydrophilic antioxidant species as compared to $\mathrm{DPPH}^{32}$. The $\mathrm{IC}_{50}$ values of ascorbic acid, YL-thyme oil, JB-thyme oil, QY-thyme oil and LD-thyme oil were $0.088,1.848,2.951,3.205$ and $4.077 \mathrm{mg} / \mathrm{mL}$, respectively. The YL-thyme oil exhibited the best antioxidant capacity with the rate of $98.2 \%$ at $2.109 \mathrm{mg} / \mathrm{mL}$. These results revealed that the YL-thyme oil possessed the highest antioxidant activity among the four regions (Fig. 5b).

Characterized by being simple, rapid, accurate and highly sensitive, DPPH and ABTS are often combined to determine the activity of $\mathrm{EOs}^{33}$. Moreover, the YL-thyme oil and JB-thyme oil showed similar DPPH and ABTS radical scavenging activity. These results were consistent with the multivariate statistical analyses (PCA and HCA), which indicated that chemical compositions of thyme oils greatly affected the antioxidant activity.

FRAP assay. FRAP assay measures the reducing potential of an antioxidant reacting with a ferric tripyridyltriazine $\left[\mathrm{Fe}^{3+}-\mathrm{TPTZ}\right]$ complex and produces a colored ferrous tripyridyltriazine $\left[\mathrm{Fe}^{2+}-\mathrm{TPTZ}\right]$, so FRAP is a reasonable screen for the ability to maintain redox status in cells or tissues ${ }^{31}$. Calibration curves $(\mathrm{Y}=0.0379 \mathrm{X}+0.0103)$, in the range of $1 \mathrm{mmol} \cdot \mathrm{L}^{-1}-33 \mathrm{mmol} \cdot \mathrm{L}^{-1}$, showed good linearity $\left(\mathrm{R}^{2} \geq 0.9992\right)$. The reducing power capacities results follow the same pattern as in case of radical scavenging assay, in which the YL-thyme oil was the most active one $\left(2.917 \mathrm{mmol} \cdot \mathrm{L}^{-1} \cdot \mathrm{g}^{-1} \mathrm{DW}\right)$, followed by that from JB $\left(2.549 \mathrm{mmol} \cdot \mathrm{L}^{-1} \cdot \mathrm{g}^{-1} \mathrm{DW}\right)$, LD $\left(2.413 \mathrm{mmol} \cdot \mathrm{L}^{-1} \cdot \mathrm{g}^{-1} \mathrm{DW}\right)$ and QY $\left(1.956 \mathrm{mmol} \cdot \mathrm{L}^{-1} \cdot \mathrm{g}^{-1} \mathrm{DW}\right)$. Comparing these results with the standard antioxidant trolox $\left(7.28 \mathrm{mmol} \cdot \mathrm{L}^{-1} \cdot \mathrm{g}^{-1} \mathrm{DW}\right)$, it was revealed that the thyme oils had significantly lower reducing potential than the standard (Fig. $5 \mathrm{c}$ ).

TBARS assay. Lipid peroxidation is an oxidative alteration of polyunsaturated fatty acids in the cell membranes that generates a number of degradation products. It can be initiated when fatty acids or fatty acyl side chains are attacked by free radicals. This oxidation process could affect the structural and functional damage of biomolecule $^{34}$. For this reason, it is necessary to determine the function of these thyme oils on lipid peroxidation 

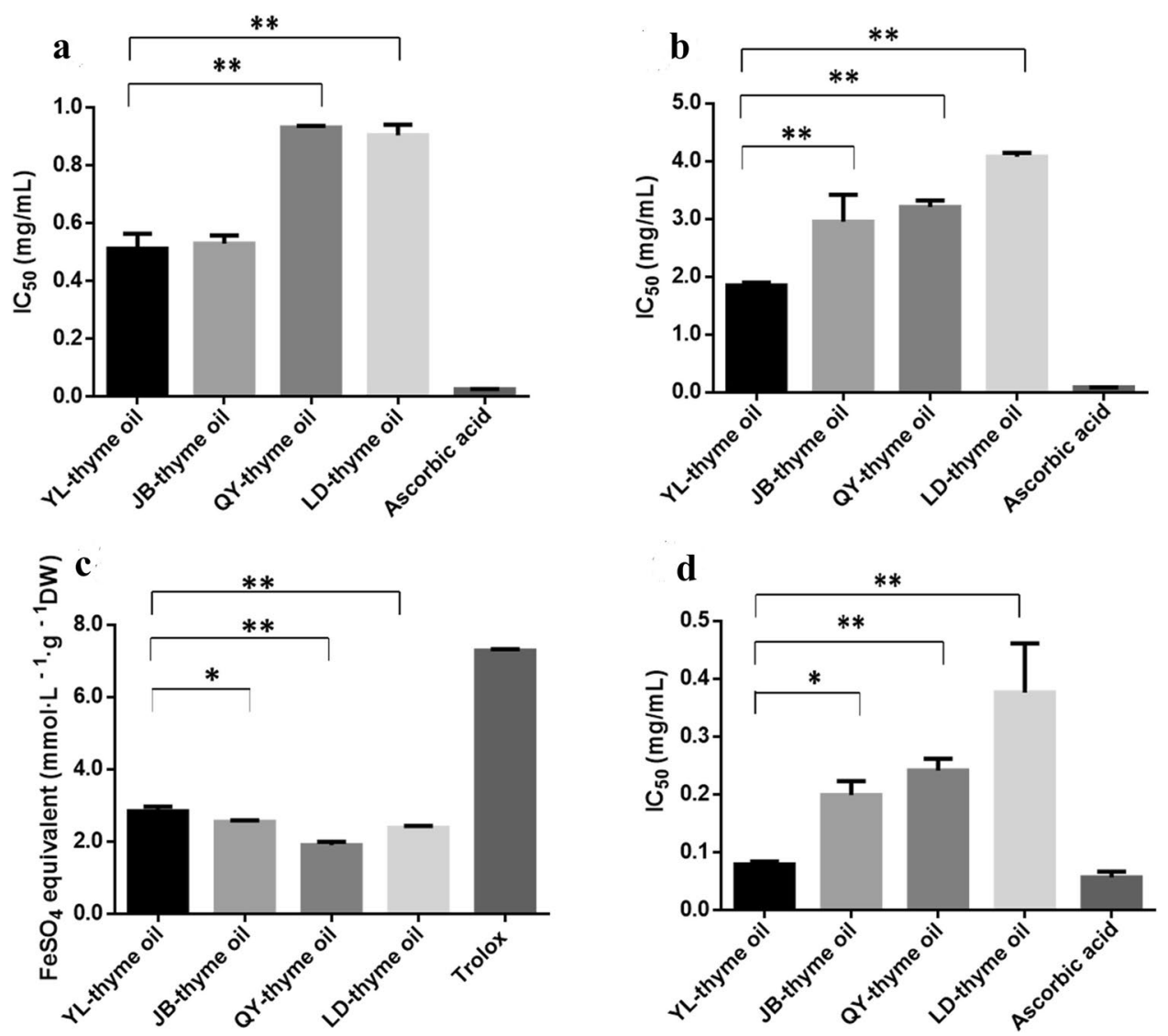

Figure 5. The $\mathrm{IC}_{50}$ value of thyme oils on DPPH (a), ABTS (b) and TBARS (d) and $\mathrm{FeSO}_{4}$ equivalent on FRAP (c). Results are presented as means $\pm \mathrm{SD}(n=3)$. ${ }^{* *}$ Represents $p$-value less than 0.01 and ${ }^{\star}$ represents $p$ value less than 0.05 .

phenomenon. In biological systems, MDA is a reactive species that participates in the cross-linking of DNA with proteins and damages liver cells ${ }^{35}$. In the present study, $\mathrm{Fe}^{2+}-\mathrm{H}_{2} \mathrm{O}_{2}$ system was used to induce lipid peroxidation in mouse liver homogenate. The lipid peroxidation inhibition effects of thyme oils increased with the increase of sample concentrations and significant differences $(p<0.05)$ among the tested thyme oils were found.

By comparing the $\mathrm{IC}_{50}$ values of YL-thyme oils with that of the authentic antioxidant ascorbic acid, it was found that the antioxidant activity of $\left(\mathrm{IC}_{50}=0.080 \mathrm{mg} / \mathrm{mL}\right)$ was quite comparable with that of ascorbic acid $\left(\mathrm{IC}_{50}=0.058 \mathrm{mg} / \mathrm{mL}\right)$. At a concentration of $0.563 \mathrm{mg} / \mathrm{mL}$, the inhibition effect of YL-thyme oil was $88.90 \%$. The others were ranked in the following order: JB-thyme oil $\left(\mathrm{IC}_{50}=0.198 \mathrm{mg} / \mathrm{mL}\right)$, QY-thyme oil $\left(\mathrm{IC}_{50}=0.241 \mathrm{mg} /\right.$ $\mathrm{mL}$ ) and LD-thyme oil $\left(\mathrm{IC}_{50}=0.376 \mathrm{mg} / \mathrm{mL}\right.$ ) (Fig. $5 \mathrm{~d}$ ). These results indicate that the thyme oils significantly inhibited MDA formation in the liver tissue and could protect cell membranes from lipid oxidation.

The correlations of thyme oil components with antioxidant activities. Furthermore, it is important to correlate and understand which compounds contribute to the different antioxidant assays, showing specific antioxidant potential for the different radicals depending on their chemical structure. The correlations between thyme oil components and antioxidant activities were reported in Table 3. It is well known that the smaller the $\mathrm{IC}_{50}$ value is, the better the antioxidant activity is. Therefore, compounds present in thyme oils showed a strong and positive correlation with the free radical scavenging activity (DPPH. and ABTS ${ }^{+}$), FRAP as well as TBARS. In contrast to this finding, $\beta$-bisabolene was inversely and strongly related to the DPPH $(0.96561, p<0.05)$. This inverse relationship would indicate that the higher content of the $\beta$-bisabolene did not exert protection, but actually promoted oxidation. Interestingly, carvacrol ethyl ether presented statistically significant positive correlations with DPPH $(-0.96372, p<0.05)$ and the Code of Federal Regulations lists it as a synthetic flavoring substance that could be safely used in foods (21CFR172.515). Carvacrol methyl ether $(-0.95213, p<0.05)$ and borneol $(-0.95411, p<0.05)$ both showed statistically significant positive correlation with DPPH. All the compounds mentioned above are on the list of flavoring substances provided by Regulation (EC) No 2232/96 of the European Parliament and of the Council, which was introduced in Annex I to Regulation (EC) No 1334/2008 of the European Parliament and of the Council.

The correlation between ABTS and compounds, including isobornyl acetate $(-0.98067, p<0.05)$, carvacrol acetate $(-0.96479, p<0.05)$ and dauca-5,8-diene $(-0.96651, p<0.05)$ was obvious. This tendency is explained by the high scavenging power of these components. Similarly, the latter two were considerably correlated with TBARS $(-0.98119$ and $-0.99426, p<0.05$, respectively) and these observations are consistent with published 


\begin{tabular}{|c|c|c|c|c|}
\hline \multirow[b]{2}{*}{ Components } & \multicolumn{4}{|c|}{ Antioxidant activity } \\
\hline & DPPH & ABTS & FRAP & TBARS \\
\hline Borneol & $-0.95708^{\star}$ & -0.89822 & 0.83123 & -0.78727 \\
\hline Carvacrol methyl ether & $-0.95469^{*}$ & -0.86998 & 0.82162 & -0.75053 \\
\hline Carvacrol ethyl ether & $-0.96665^{*}$ & -0.93093 & 0.85974 & -0.83460 \\
\hline$\beta$-Bisabolene & $0.96544^{*}$ & 0.81295 & -0.86444 & 0.70027 \\
\hline Artemisia triene & -0.72122 & -0.92462 & 0.76939 & $-0.96586^{*}$ \\
\hline$\alpha$-Terpinne & -0.72122 & -0.92462 & 0.76939 & $-0.96586^{*}$ \\
\hline (Z)-Tagetone & -0.72122 & -0.92462 & 0.76939 & $-0.96586^{*}$ \\
\hline Isobornyl acetate & -0.88440 & $-0.98067^{\star}$ & 0.82587 & -0.93715 \\
\hline Dihydrocitronellol acetate & -0.72122 & -0.92462 & 0.76939 & -0.96586 \\
\hline 4'-Methoxy-Acetophenone & -0.72122 & -0.92462 & 0.76939 & $-0.96586^{*}$ \\
\hline Eugenol & -0.71360 & -0.91657 & 0.77973 & $-0.96836^{*}$ \\
\hline Carvacrol acetate & -0.79902 & $-0.96479^{\star}$ & 0.81926 & $-0.98119^{*}$ \\
\hline$\beta$-Cedrene & -0.72122 & -0.92462 & 0.76939 & $-0.96586^{*}$ \\
\hline Dauca-5,8-diene & -0.81422 & $-0.96651^{*}$ & 0.85879 & $-0.99426^{*}$ \\
\hline trans-Cadina-1(6),4-diene & -0.72122 & -0.92462 & 0.76939 & $-0.96586^{*}$ \\
\hline Spathulenol & -0.72122 & -0.92462 & 0.76939 & $-0.96586^{*}$ \\
\hline Viridiflorol & -0.72122 & -0.92462 & 0.76939 & -0.96585 \\
\hline a-Acorenol & -0.72122 & -0.92462 & 0.76939 & $-0.96586^{*}$ \\
\hline Caryophylla-4(12),8(13)-dien-5 $\beta$-ol & -0.72122 & -0.92462 & 0.76939 & -0.96586 \\
\hline$\delta$-Amorphene & -0.68532 & -0.88631 & 0.79189 & $-0.96065^{*}$ \\
\hline
\end{tabular}

Table 3. The correlations between thyme oil components and antioxidant activities. ${ }^{*}$ and ${ }^{*}$ : significant at the 0.01 and 0.05 probability levels, respectively.

data $^{36}$. However, for FRAP, all of them were not statistically significant. These compounds mentioned above were found in the highest amounts in the YL and JB thyme-oil. This indicated that the higher level of these components is likely to be closely related to the relatively high antioxidant activity of YL and JB-thyme oil. These differences observed between assays are related to the individual molecular structure of each compound which indicated that stereoisomerism, functional groups distribution and any other structural parameters such as the oxidation state of the $\mathrm{C}$ ring, the hydroxylation and methylation pattern also are expected to affect the final value. In particular, there were good correlations of carvacrol ethyl ether both with $\mathrm{IC}_{50}$ value of $\mathrm{DPPH}$ and ABTS and carvacrol acetate both with $\mathrm{IC}_{50}$ value of ABTS and TBARS, which could be recommended as an indicative component for the antioxidant capacity. It is acknowledged that carvacrol is used to defined the quality of the Thymus species and widely used in the food industry as antimicrobial and antioxidant agent. Thus, in the present work, carvacrol methyl ether, carvacrol ethyl ether and carvacrol acetate were all found to be significantly associated with antioxidant activity, implying the carvacrol analogues as potential natural antioxidants of thyme oils from Loess Plateau in China.

In vivo antioxidant activity of thyme oil on the zebrafish. Although in vitro assays are used for rapid screening but their results cannot be directly extrapolated to in vivo conditions. The experimental models are therefore used to simulate in vivo conditions. Hence, we also evaluated the antioxidant capacity of thyme oils using zebrafish model.

Lethal and teratogenic effects of thyme oil. To determine the toxicity of thyme oils, we investigated the survival rate of zebrafish larvae. The thyme oil had no toxic effect up to $40 \mu \mathrm{g} / \mathrm{mL}$. Therefore, concentrations of thyme oil less than $40 \mu \mathrm{g} / \mathrm{mL}$ are suitable for the in vivo experiments.

When the concentration reached $40 \mu \mathrm{g} / \mathrm{mL}$, these larvae treated with the thyme oils at $48 \mathrm{hpf}$ from four producing areas showed different degrees of morphological abnormalities, including yolk sac edema, pericardial edema, and curved body shape (Fig. 6a). Pericardial edema and yolk sac edema were the most pronounced morphological alterations. Pericardial edema was first observed in the LD-thyme oil and all zebrafish larvae in this group were dead at the concentration of $40 \mu \mathrm{g} / \mathrm{mL}$. The curved body shape was first observed in the QY-thyme oil at the concentration of $40 \mu \mathrm{g} / \mathrm{mL}$.

Figure $6 \mathrm{~b}$ shows the lethal effects of thyme oil at $48 \mathrm{hpf}$ and mortality rates in the treatment group exhibited a dose and time-dependent increase. The values of the $1 / 3 \mathrm{LC}_{1}, \mathrm{LC}_{1}$ and $\mathrm{LC}_{10}$ of the four thyme oils were determined to be around 5, 10 and $20 \mu \mathrm{g} / \mathrm{mL}$.

Antioxidant activity in Tg (krt4: NTR-hKikGR) ${ }^{\text {cy17 }}$ zebrafish larvae. The in vivo capability of thyme oils on inhibiting oxidative stress was further evaluated using MTZ-induced oxidative insult in Tg (krt4: NTRhKikGR) ${ }^{\text {cy17 }}$ transgenic zebrafish model. A transgenic line of Tg (krt4:NTR-hKikGR ${ }^{\text {cyl7 }}$ is established which 
$\mathbf{a}$

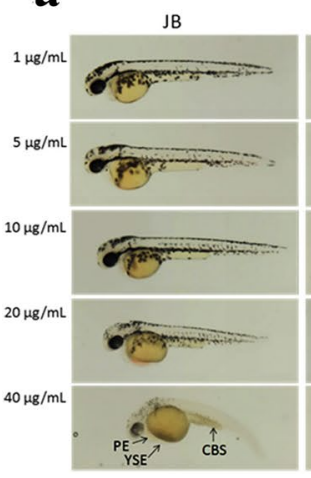

$\mathrm{YL}$

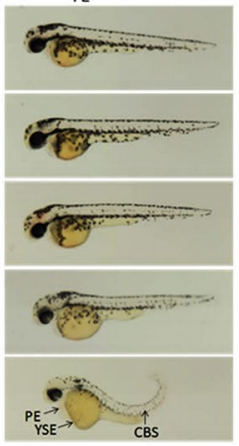

QY

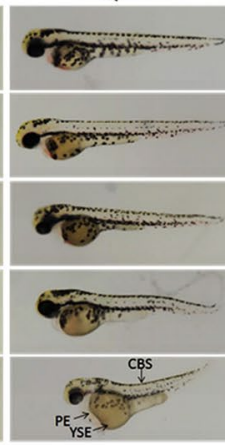

LD

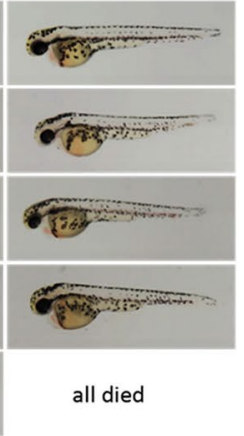

b

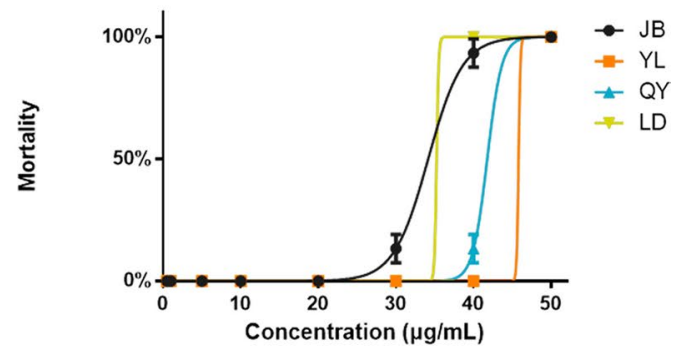

Figure 6. The toxicity of thyme oils in zebrafish larvae (a). Mortality curves until $48 \mathrm{hpf}(\mathbf{b})$. Results are presented as means \pm SD $(n=15)$. YSE: yolk sac edema; PE: pericardial edema; CBS: curved body shape.

a

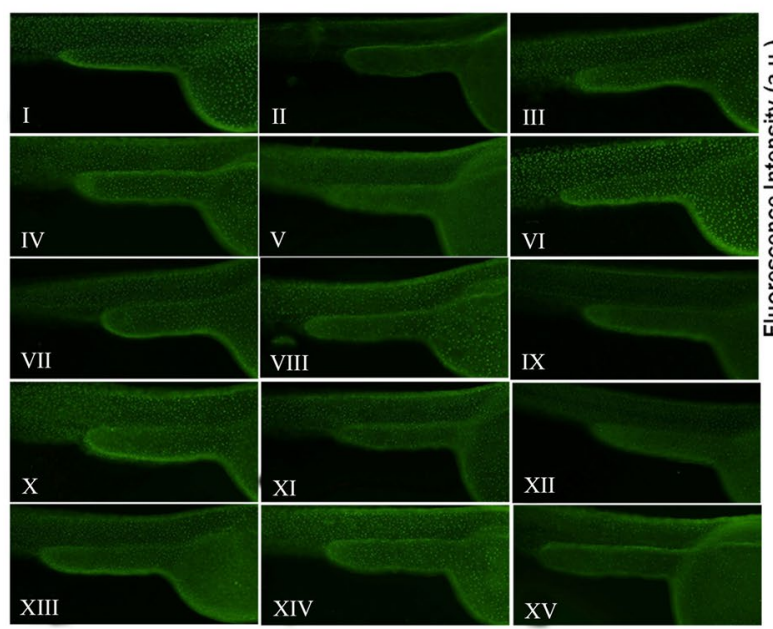

b

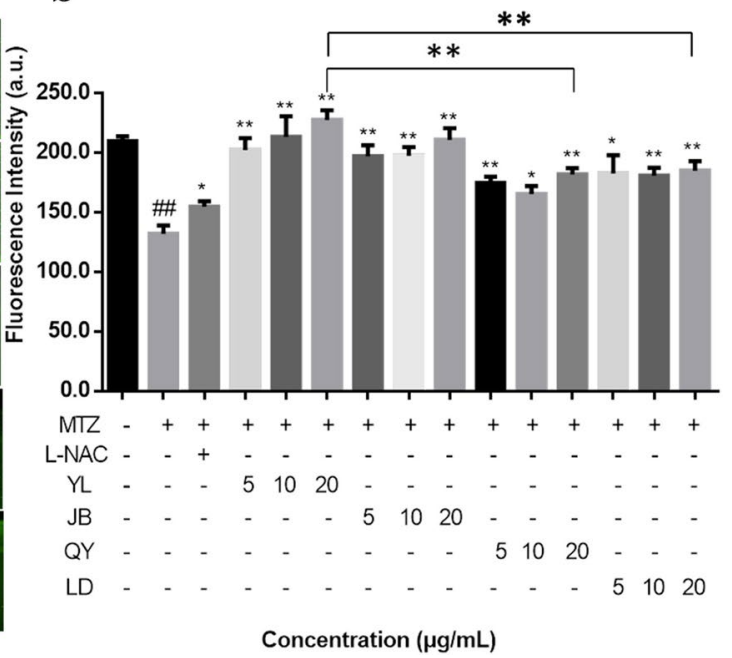

Figure 7. Thyme oils inhibited MTZ-induced oxidative insults in skin cells of Tg (krt4: NTR-hKikGR) ${ }^{\text {cyl7 }}$ transgenic zebrafish (a): Control group (I); MTZ-treatment group (II); MTZ+L-NAC-treatment gruop (III); MTZ + YL-thyme oil-treatment group at the concentration of $5 \mu \mathrm{g} / \mathrm{mL}$ (IV), $10 \mu \mathrm{g} / \mathrm{mL}$ (V) and $20 \mu \mathrm{g} / \mathrm{mL}$ (VI); $\mathrm{MTZ}+\mathrm{JB}$-thyme oil-treatment group at the concentration of $5 \mu \mathrm{g} / \mathrm{mL}$ (VII), $10 \mu \mathrm{g} / \mathrm{mL}$ (VIII) and $20 \mu \mathrm{g} / \mathrm{mL}$ (IX); MTZ+QY-thyme oil-treatment group at the concentration of $5 \mu \mathrm{g} / \mathrm{mL}(\mathrm{X}), 10 \mu \mathrm{g} / \mathrm{mL}$ (XI) and $20 \mu \mathrm{g} / \mathrm{mL}$ (XII); MTZ + LD-thyme oil-treatment group at the concentration of $5 \mu \mathrm{g} / \mathrm{mL}$ (XIII), $10 \mu \mathrm{g} / \mathrm{mL}$ (XIV) and $20 \mu \mathrm{g} /$ $\mathrm{mL}(\mathrm{XV})$; Determination of fluorescence intensity by Image analysis (b); The values are expressed as mean \pm SD $(n=15) .{ }^{\star}$ Represents $p$-value less than 0.05 and ${ }^{\star *}$ represents $p$-value less than 0.01 vs. MTZ group; \# represents $p$ value less than 0.05 and \#\# represents $p$ value less than 0.01 vs. control group.

overexpresses the NTR-hKikGR fusion protein under the control of the skin-specific krt4 promoter. It provides as a unique quantitative and fast tool to study the signaling molecules which modulate skin apoptosis in living animals ${ }^{37}$. The fluorescence spots of zebrafish are shown in Fig. 7a. and the anti-oxidation results of the thyme oil on transgenic zebrafish treated with MTZ are shown in Fig. 7b. The results showed that the number of fluorescence spots on the epidermal cells of the zebrafish was significantly decreased after the addition of MTZ. In the treatment of different concentrations of thyme oils $(5,10$ and $20 \mu \mathrm{g} / \mathrm{mL})$, the number of fluorescence spots on the epidermal cells increased significantly compared with the MTZ-treatment group, indicating that the thyme oils can resist the overproduction of ROS and skin cell apoptosis induced by MTZ. The antioxidant capacity of the thyme oils is better than that of the L-NAC-treatment group, especially the antioxidant capacity of YL-thyme oil is the most prominent, followed by that from JB-thyme oil, QY-thyme oil and LD-thyme oil.

Protective effects of thyme oil on ROS generation in AAPH-induced oxidative stress. The antioxidative effect of thyme oil on ROS production in zebrafish larvae was examined by detection of DCFDA. Fluorescent photographs of larvae showed that the untreated zebrafish had low fluorescence intensity, whereas AAPH-induced group generated a marked increase in the observed fluorescence intensity, indicating that ROS was produced in the presence of AAPH in the zebrafish larvae. 
$\mathbf{a}$

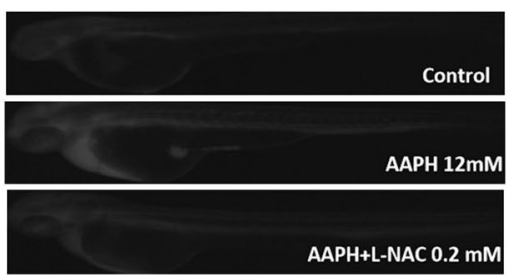

b

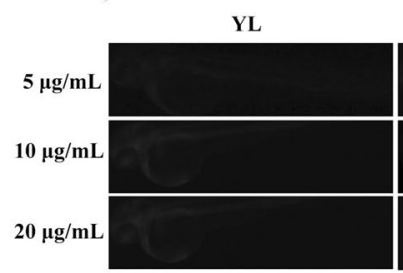

JB
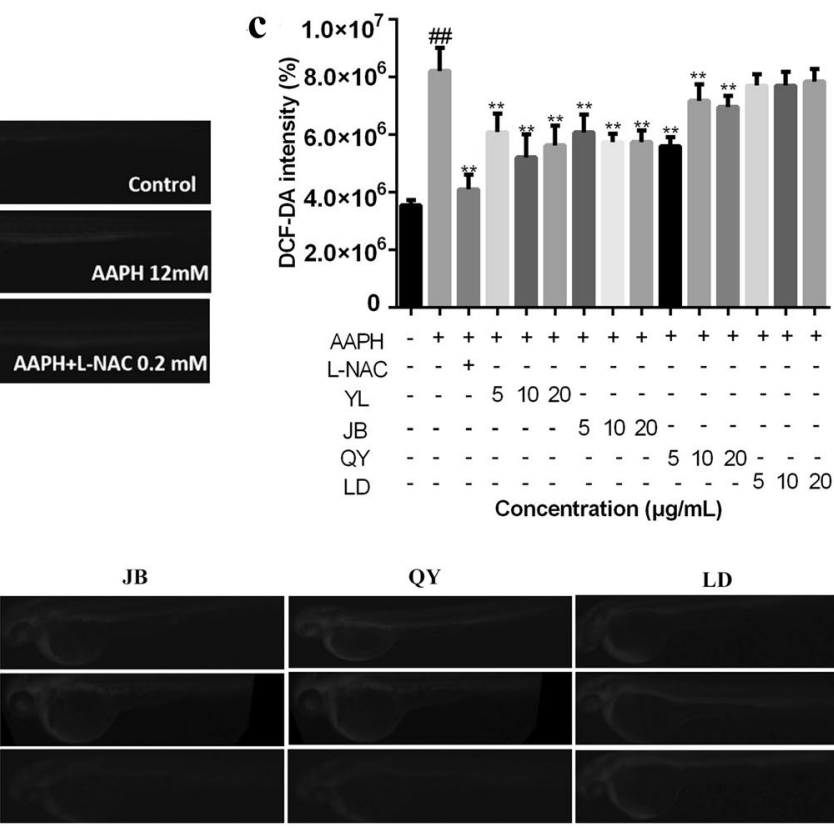

QY

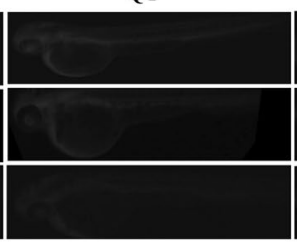

LD

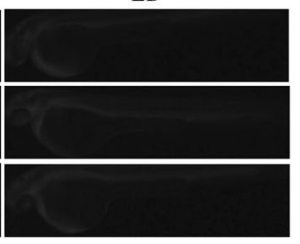

Figure 8. Determination of ROS levels in zebrafish larvae from $48 \mathrm{hpf}$ in Control group, AAPH-treatment group, AAPH + L-NAC-treatment group (a); Determination of ROS levels in zebrafish larvae from $48 \mathrm{hpf}$ after treatment with YL-thyme oil, JB-thyme oil, QY-thyme oil and LD-thyme oil (b); Determination of mean DCF fluorescence intensity by Image analysis $(\mathbf{c})$. The values are expressed as mean $\pm \operatorname{SD}(n=15) .{ }^{\star}$ Represents $p$-value less than 0.05 and ${ }^{* *}$ represents $p$ value less than 0.01 vs. AAPH-induced group; \# represents $p$-value less than 0.05 and \#\# represents $p$-value less than 0.01 vs. control group.

The scavenging efficacy of the thyme oil on the ROS production in AAPH-induced zebrafish larvae was measured. At $48 \mathrm{hpf}$, the larvae in the YL-thyme oil-treatment and JB-thyme oil-treatment groups (Fig. 8b) exhibited markedly lower fluorescence intensities than those in the AAPH-treatment group (Fig. 8a), which indicated that ROS significantly decreased after thyme oil exposure. Conversely, fluorescence intensity in QY-thyme oil-treatment and LD-thyme oil-treatment groups (Fig. 8c) did not decrease significantly compared to the AAPH-treatment group. Hence, these results indicate that thyme oil are effective antioxidants in AAPHinduced oxidative stress model.

Mechanism of YL-thyme oil on the AAPH-induced zebrafish larvae. The outstanding in vitro and in vivo antioxidant activities presented above gave an indisputable confirmation that YL-thyme oil and JB-thyme oil showed better antioxidant activities due to the close distance between two of them. YL-thyme oil exerted the best antioxidant activity among the four regions and further studies are required to elucidate the biological mechanisms and signaling pathways underlying the protective effects of the thyme oil.

Effects of YL-thyme oil on MDA Levels, SOD and CAT activities in AAPH-induced zebrafish larvae. The antioxidant enzymes, SOD and CAT, work within the cells to remove most of superoxides and peroxides before they react with metal ions to form more reactive free radicals. SOD, the first line of defense against free radicals, converts the superoxide radical to $\mathrm{H}_{2} \mathrm{O}_{2}$ and $\mathrm{O}_{2}$ by reduction. The $\mathrm{H}_{2} \mathrm{O}_{2}$ is transformed into water and oxygen by $\mathrm{CAT}^{38}$. MDA, an end product of lipid peroxidation, represented the level of lipid peroxidation $^{39}$.

The MDA levels and antioxidant enzymes activities (SOD and CAT) were examined and shown in Fig. 9. AAPH-induction decreased the activities of SOD, and CAT in zebrafish and increased MDA levels when compared to control group, whereas AAPH-induced zebrafish protected by YL-thyme oil showed remarkable damage prevention. After being treated with YL-thyme oil $(5 \mu \mathrm{g} / \mathrm{mL})$, the activities of SOD and CAT were increased by 1.30 folds, and MDA level decreased by $75 \%$ as compared with those of AAPH-induced group. The results implied that the protective effect of YL-thyme oil against oxidative stress might be rationalized because of the impairment of antioxidant defenses system. Obviously, AAPH damaged the antioxidant defense system and promoted the lipid peroxidation by reducing the activities of the antioxidation enzymes and upregulating the formation of MDA in zebrafish, while YL-thyme oil could prevent these harms.

Effects of YL-thyme oil on gene expression. In order to investigate the mechanism of YL-thyme oil-treated antioxidant activity, the mRNA expression levels of genes related to the antioxidant activities were measured (Fig. 10). Nrf2 and its endogenous inhibitor, Keap1, function as a ubiquitous, evolutionarily conserved intracellular defense mechanism to counteract oxidative stress and the Keap1/Nrf2 signaling pathway is an 
a

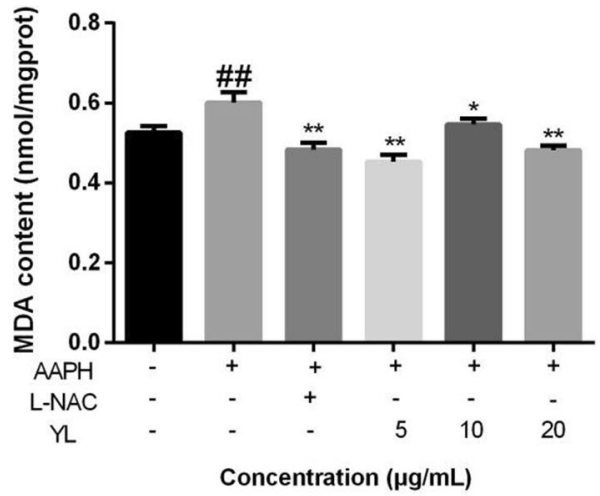

b

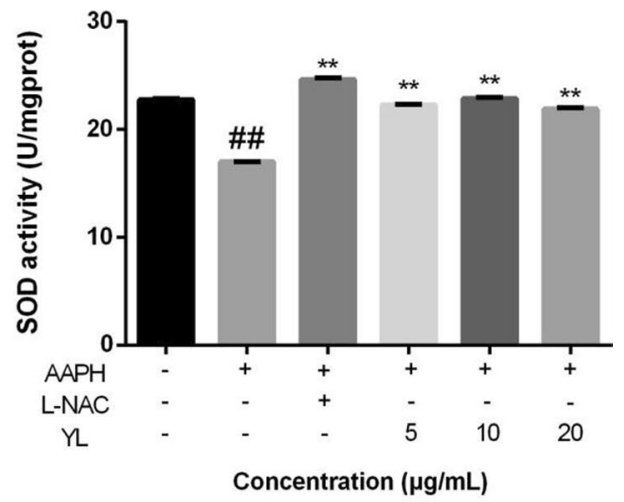

c

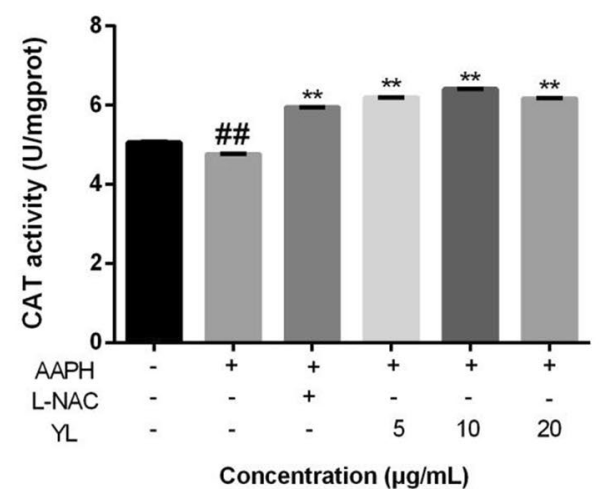

Figure 9. Effects of YL-thyme oil on levels of MDA and antioxidant enzymes activity in AAPH-induced zebrafish larvae. MDA level (a), SOD activity (b) and CAT activity (c) were examined after incubation. The values are expressed as mean \pm SD $(n=3){ }^{*}$ Represents $p$-value less than 0.05 and ${ }^{* *}$ represents $p$-value less than 0.01 vs. AAPH-induced group; \# represents $p$-value less than 0.05 and \#\# represents $p$ value less than 0.01 vs. control group.

important regulatory component of cells in a steady-state environment, protecting cells from oxidative stress ${ }^{5}$. Moreover, Nrf2/Hmoxl pathway is widely studied in vertebrates and play a pivotal role in neurodegenerative disorders. Hmox1, as Nrf2-dependent gene, provides cytoprotective effect and play a crucial role in the development of oxidative and age-related disorders ${ }^{40}$. Also, Hmox1 is known to play an important role in cellular protection against oxidative insult in cardiovascular disease, including diabetes, and in the alleviation of vascular diseases and various chemical reagents were known to facilitate antioxidant response via activating Hmox1 expression ${ }^{41}$. In the present study, YL-thyme oil-treated zebrafish larvae exhibited significant downregulation of Keap1 expression and upregulation of Nrf2 expression; furthermore, the expression level of Sod1, Cat and Hmoxl were significantly increased in the treatment of YL-thyme oil groups. AAPH-induction decreased the expression of Sod1, Cat, Nrf2 and Hmox1 in zebrafish by 1.39, 1.41, 2.03 and 2.02 folds, respectively and increased Keap 1 levels by 3.47 folds when compared to control group. In the YL-thyme oil-treatment group and L-NAC-treatment group, the expression levels of genes encoding the Sod1 (Fig. 10a) and Nrf2 (Fig. 10d) were significantly increased relative to that in the AAPH-treatment groups. The expression levels of genes encoding Cat (Fig. 10b) and Hmox1 (Fig. 10e) were significantly increased relative to the AAPH-treatment group; however, no obvious changes were detected in the L-NAC-treatment groups relative to the control groups. In contrast, the expression levels of genes encoding Keap1 was downregulated in the YL-thyme oil-treatment group (Fig. 10c). Taken together, our data demonstrated that thyme oil might exert the antioxidant activity in AAPH-induced oxidative stress model by activating the cellular Nrf2/Keap1 pathway.

\section{Conclusions}

This is the first study on the chemical constituents, antioxidant activities and biological mechanism of EOs of T. quinquecostatus. One new natural compound, carvacrol ethyl ether, was firstly discovered in the thyme oils. It has been used as a synthetic flavoring substance with no safety concern. The thyme oils from the four regions were classified into three groups by chemometric analysis, out of which the borneol, isobornyl acetate, carvacrol methyl ether, $\rho$-vinyl guaiacol, thymol, carvacrol ethyl ether and linalool contributed the most to the classification, indicating that these compounds may be used for the geographical markers of the thyme oils. The YL-thyme oil was found to produce superior EO yields and possess the strongest anti-oxidant activities in vitro 
$\mathbf{a}$

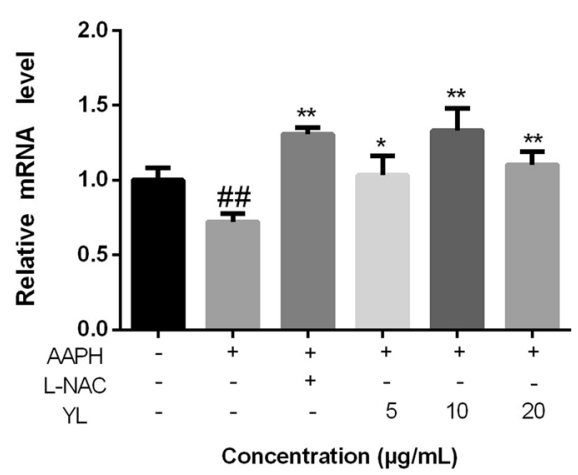

c

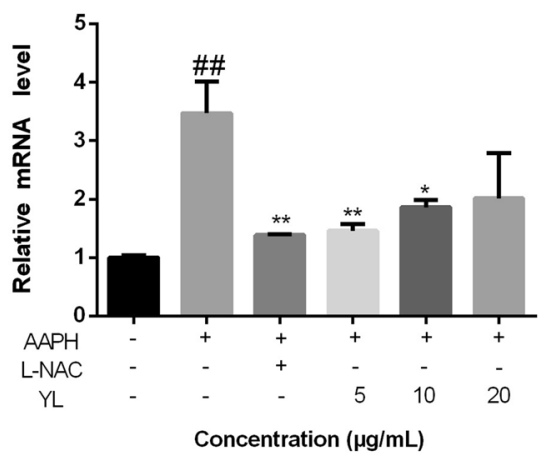

e

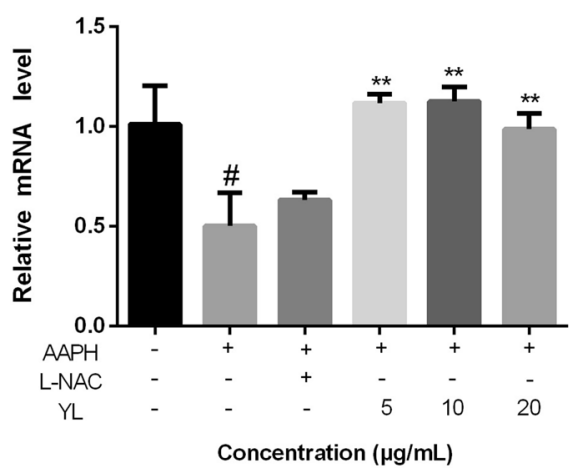

b CAT

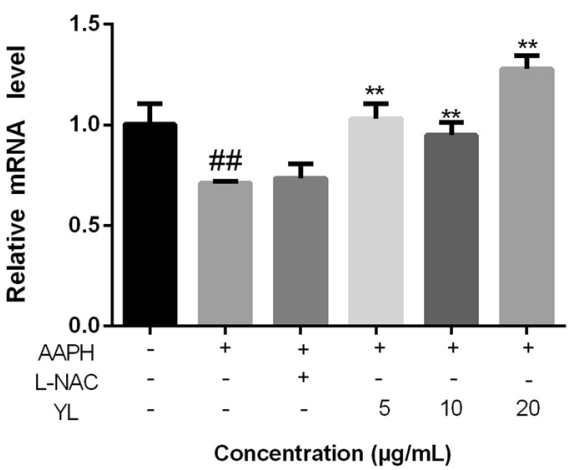

d

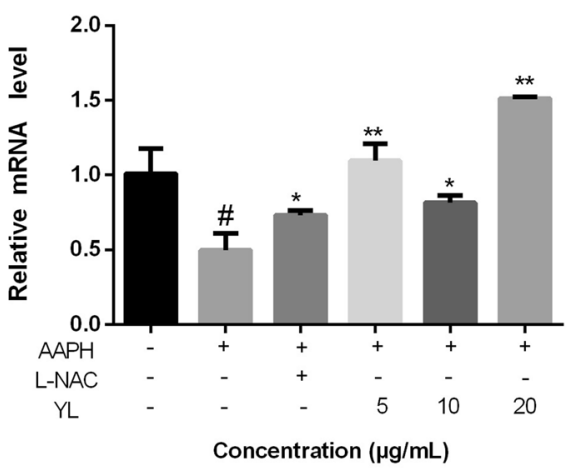

Figure 10. Effects of thyme oil gene expression in zebrafish larvae at $48 \mathrm{hpf}$. The mRNA levels of Sod1 (a), Cat (b), Keap1 (c) and Hmox1 (d) on YL-thyme oil. The values are expressed as mean $\pm \mathrm{SD}(n=3) .{ }^{*}$ Represents $p$-value less than 0.05 and ${ }^{* *}$ represents $p$ value less than 0.01 vs. AAPH-induced group; \# represents $p$ value less than 0.05 and \#\# represents $p$-value less than 0.01 vs. control group.

and in vivo, suggesting that domestication of this thyme oil is economical for the food industry. It was also proved with correlation analysis that borneol, carvacrol methyl ether, carvacrol ethyl ether, carvacrol acetate, isobornyl acetate and dauca-5,8-diene could be the characteristic constituents responsible for the antioxidant effect of the thyme oils. This indicated that the carvacrol analogues might be developed as potential natural antioxidants of thyme oils from Loess Plateau in China. Furthermore, Keap1/Nrf2 pathway contributed to the anti-oxidant processes of YL-thyme oil. Taken together, our results suggest that thyme oil could be useful as the natural antioxidant and have the potentiality of enhancing the protective effect against oxidative stress. The findings of the present study can provide new insights for enhancing the valuable components and antioxidant capacity of this plant in their EOs. Therefore, this study could lay foundation for the applications of thyme oils in food, pharmaceutical and cosmetic industry, and also provide promising sources for natural antioxidants and 
a new possible breakthrough point for further bioactivity studies of thyme. Admittedly, there are limitations to the current study. CC-MS has been used to quantified the thyme oils components and we didn't examine the data further by GC-FID which might be more precise than GC-MS in quantifying complex mixtures. In addition, we cannot completely determine the major contribution of components for the antioxidant activities of thyme oils. The potential antioxidants, especially the carvacrol analogues from the correlation analysis should be assessed in future studies. Furthermore, further studies can be performed to delineate other candidate genes and signaling pathways, especially those closely correlated with anti-oxidation, in thyme oils-mediated effects.

Ethics statement. All experimental procedures were carried out in accordance with the National Institute of Health Guide for the Care and Use of Laboratory Animals and approved by the Experimental Animal Ethics Committee of the Academic Committee of Beijing University of Chinese Medicine.

Received: 25 April 2020; Accepted: 19 June 2020

Published online: 09 July 2020

\section{References}

1. Duračková, Z. Some current insights into oxidative stress. Physiol. Res. 59, 459 (2010).

2. Reuter, S., Gupta, S. C., Chaturvedi, M. M. \& Aggarwal, B. B. Oxidative stress, inflammation, and cancer: how are they linked?. Free Radical Bio. Med. 49, 1603-1616 (2010).

3. Rajendran, P. et al. Antioxidants and human diseases. Clin. Chim. Acta. 436, 332-347 (2014)

4. Li, Q. et al. Dietary l-arginine supplementation alleviates liver injury caused by escherichia coli LPS in weaned pigs. Innate Immun. 18, 804-814 (2012).

5. Deshmukh, P., Unni, S., Krishnappa, G. \& Padmanabhan, B. The keap1-nrf2 pathway: promising therapeutic target to counteract ros-mediated damage in cancers and neurodegenerative diseases. Biophys. Rev. 9, 41-56 (2017).

6. Milella, L., Bader, A., De Tommasi, N., Russo, D. \& Braca, A. Antioxidant and free radical-scavenging activity of constituents from two scorzonera species. Food Chem. 160, 298-304 (2014).

7. Stahl-Biskup, E. \& Venskutonis, R. P. Handbook of Herbs and Spices (Second edition), Woodhead Publishing Series in Food Science, Technology and Nutrition. 1, 499-525 (2012).

8. Yan, C. et al. Antioxidant activities and chemical compositions of Thymus quinquecostatus Celak. J. Beijing Univ. Tradit. Chin. Med. 39, 383-389 (2016).

9. Chang, Y. L. et al. Multi-response extraction optimization based on anti-oxidative activity and quality evaluation by main indicator ingredients coupled with chemometric analysis on Thymus quinquecostatus Celak. Molecules 23, 957 (2018).

10. Nikoli, M. et al. Chemical composition, antimicrobial, antioxidant and antitumor activity of Thymus serpyllum L., Thymus algeriensis Boiss. and Reut and Thymus vulgaris L. essential oils. Ind. Crop. Prod. 52, 183-190 (2014).

11. Vandendool, H. \& Kratz, P. D. A generalization of the retention index system including linear temperature programmed gas-liquid partition chromatography. J. Chromatogr. A. 11, 463-471 (1963).

12. Hedhili, L., Romdhane, M., Planche, H. \& Abderrabba, M. Towards gas chromatography-mass spectrometry coupling protocols for both identifying and quantification essential oils of Thymus capitatus Hoff et Link. J. Chromatogr. A. 1064, 129-134 (2005).

13. Goodner, K. L., Mahattanatawee, K., Plotto, A., Sotomayor, J. A. \& Jordan, M. J. Aromatic profiles of Thymus hyemalis and Spanish T. vulgaris essential oils by GC-MS/GC-O. Ind. Crop. Prod. 24, 264-268 (2006).

14. Kirby, A. J. \& Schmidt, R. J. The antioxidant activity of chinese herbs for eczema and of placebo herbs-i. J. Ethnopharmacol. 56, 103-108 (1997).

15. Re, R. et al. Antioxidant activity applying an improved ABTS radical cation decolorization assay. Free Radical Biol. Med. 26, 1231-1237 (1999).

16. Benzie, I. F. \& Strain, J. J. The ferric reducing ability of plasma (FRAP) as a measure of "antioxidant power": the FRAP assay. Anal. Biochem. 239, 70-76 (1996).

17. Ohkawa, H., Ohishi, N. \& Yagi, K. Assay for lipid peroxides in animal tissues by thiobarbituric acid reaction. Anal. Biochem. 95, 351-358 (1979).

18. Xia, Q. et al. Psoralen induces developmental toxicity in zebrafish embryos/larvae through oxidative stress, apoptosis, and energy metabolism disorder. Front. Pharmacol. https://doi.org/10.3389/fphar.2018.01457 (2018).

19. Aruoma, O., Halliwell, B., Hoey, B. \& Butler, J. The antioxidant action of N-acetylcysteine: its reaction with hydrogen peroxide, hydroxyl radical, superoxide, and hypochlorous acid. Free Radical Biol. Med. 6, 593-597 (1989).

20. Bourguiba, I., Zahlila, A., BouaïCha, N., Amri, M. \& Mezghani, S. Antioxidant effect of the marine green alga ulva rigida ethanolic precipitate in yeast cells and zebrafish embryos. S. Afr. J. Bot. 113, 253-260 (2017).

21. Rosenkranz, A. R., Schmaldienst, S., Stuhlmeier, K. M., Chen, W. \& Zlabinger, G. J. A microplate assay for the detection of oxidative products using 2',7'-dichlorofluorescin-diacetate. J. Immunol. Methods. 156, 39-45 (1992).

22. Smith, P. K. et al. Measurement of protein using bicinchoninic acid. Anal. Biochem. 150, $76-85$ (1985).

23. Nowak, A., Kalemba, D., Krala, L., Piotrowska, M. \& Czyzowska, A. The effects of thyme (Thymus vulgaris) and rosemary (Rosmarinus officinalis) essential oils on Brochothrix thermosphacta and on the shelf life of beef packaged in high-oxygen modified atmosphere. Food Microbiol. 32, 212-216 (2012).

24. Asanova, Z. K. et al. Biological activity of 1,8-Cineole from Levant Wormwood. Pharm. Chem. J. 37, 28-30 (2003).

25. Zhang, R., Mi, S. Q. \& Wang, N. S. Effect of borneol on cytochrome P450 3A enzyme and midazolam pharmacokinetics in rats. Eur. J. Drug Metab. Ph. 38, 159-169 (2013).

26. Zeljković, S. Ć \& Maksimović, M. Chemical composition and bioactivity of essential oil from Thymus species in Balkan Peninsula. Phytochem. Rev. 14, 335-352 (2015).

27. Chen, Y., Li, L., Long, L. \& Ding, S. High cell-density cultivation of phenolic acid decarboxylase-expressing Escherichia coli and 4-vinylguaiacol bioproduction from ferulic acid by whole-cell catalysis. J. Chem. Technol. Biot. 93, 2415-2421 (2018).

28. Olaizola, C. et al. Experience with thymol in chloroform solution for the treatment of paronychia. Mycopathologia 159, 209-211 (2005).

29. Granato, D., Santos, J. S., Escher, G. B., Ferreira, B. L. \& Maggio, R. M. Use of principal component analysis (PCA) and hierarchical cluster analysis (HCA) for multivariate association between bioactive compounds and functional properties in foods: a critical perspective. Trends Food Sci. Tech. 72, 83-90 (2018).

30. Johnson, S. C. Hierarchical clustering schemes. Psychometrika 32, 241-254 (1967).

31. Prior, R. L., Wu, X. \& Schaich, K. Standardized methods for the determination of antioxidant capacity and phenolics in foods and dietary supplements. J. Agric. Food Chem. 53, 4290-4302 (2005).

32. Atere, T. G., Akinloye, O. A., Ugbaja, R. N., Ojo, D. A. \& Dealtry, G. In vitro antioxidant capacity and free radical scavenging evaluation of standardized extract of Costus afer leaf. FSHW. 7, 266-272 (2018). 
33. Moon, J. K. \& Shibamoto, T. Antioxidant assays for plant and food components. J. Agric. Food Chem. 57, 1655-1666 (2009).

34. Duan, S. Y. et al. Preparation, characteristics, and antioxidant activities of carboxymethylated polysaccharides from blackcurrant fruits. Int. J. Biol. Macromol. 195, 576-585 (2019).

35. Kubow \& Stan. Toxicity of dietary lipid peroxidation products. Trends Food Sci. Tech. 1, 67-71 (1990).

36. Luo, W. Q. et al. Phytochemical composition and bioactivities of essential oils from six Lamiaceae species. Ind. Crop. Prod. 133, 357-364 (2019).

37. Chen, C. F. et al. Establishment of a transgenic zebrafish line for superficial skin ablation and functional validation of apoptosis modulators in vivo. PLoS ONE 6, e20654. https://doi.org/10.1371/journal.pone.0020654 (2011).

38. Willcox, J. K., Ash, S. L. \& Catignani, G. L. Antioxidants and prevention of chronic disease. Crit. Rev. Food Sci. 44, 275-295 (2004).

39. Hsieh, Y. Y., Chang, C. C. \& Lin, C. S. Seminal malondialdehyde concentration but not glutathione peroxidase activity is negatively correlated with seminal concentration and motility. Int. J. Biol. Sci. 2, 23-29 (2006).

40. Loboda, A., Damulewicz, M., Pyza, E., Jozkowicz, A. \& Dulak, J. Role of nrf2/ho-1 system in development, oxidative stress response and diseases: an evolutionarily conserved mechanism. Cell. Mol. Life Sci. 73, 3221-3247 (2016).

41. Issan, Y. et al. Heme oxygenase-1 induction improves cardiac function following myocardial ischemia by reducing oxidative stress. PLoS ONE 9, e92246. https://doi.org/10.1371/journal.pone.0092246 (2014).

\title{
Acknowledgements
}

The authors gratefully acknowledge the financial support of National Natural Science Foundation of China (No. 81760769), the Ningxia Hui Autonomous Region key research and development program (2020BFG03007), and the Fundamental Research Funds for the Central Universities (2018-JYBZZ-JS017).

\section{Author contributions}

T.H. carried out the in vitro and in vivo antioxidant experiment, analysed the data collected, interpreted the results and wrote the main manuscript. X.L. and S.S. performed GC-MS analysis. X.L., X.Y. and X.R. revised the manuscript. X.W. and X.X. prepared the figures. Y.D., X.L. and Y.W. prepared the tables. G.S., Q.X. and H.S. designed and supervised the experiment at various stages and assisted in the revision of the manuscript with critical inputs. All authors read the final manuscript and agreed to its submission.

\section{Competing interests}

The authors declare no competing interests.

\section{Additional information}

Correspondence and requests for materials should be addressed to Q.X. or G.S.

Reprints and permissions information is available at www.nature.com/reprints.

Publisher's note Springer Nature remains neutral with regard to jurisdictional claims in published maps and institutional affiliations.

\begin{abstract}
(c) (1) Open Access This article is licensed under a Creative Commons Attribution 4.0 International cc) License, which permits use, sharing, adaptation, distribution and reproduction in any medium or format, as long as you give appropriate credit to the original author(s) and the source, provide a link to the Creative Commons license, and indicate if changes were made. The images or other third party material in this article are included in the articleГÇÖs Creative Commons license, unless indicated otherwise in a credit line to the material. If material is not included in the articleГÇÖs Creative Commons license and your intended use is not permitted by statutory regulation or exceeds the permitted use, you will need to obtain permission directly from the copyright holder. To view a copy of this license, visit http://creativecommons.org/licenses/by/4.0/.
\end{abstract}

(C) The Author(s) 2020 